\title{
What drives exchange rates? Reassessing currency return predictability
}

\author{
Sara Ferreira Filipe ${ }^{1} \quad$ Paulo Maio ${ }^{2}$
}

First draft: April 2012

This version: October $2014^{3}$

\footnotetext{
${ }^{1}$ Luxembourg School of Finance. E-mail: sara.ferreira@uni.lu.

${ }^{2}$ Hanken School of Economics, Department of Finance and Statistics. E-mail: paulofmaio@gmail.com.

${ }^{3}$ We thank John Campbell for providing feedback on a preliminary draft and Pedro Barroso for providing exchange rate data. A previous draft was titled "What drives exchange rates?". All errors are ours.
} 


\begin{abstract}
We compute a variance decomposition for the log exchange rate based on a present-value relation. At long horizons, return predictability drives the variation in the exchange rate while predictability of future interest rate differentials plays a secondary role. At shorter horizons, the dominant source is predictability of the future spot rate. There is more return predictability and less interest spread and exchange rate predictability in the case of real exchange rates compared to nominal exchange rates. An alternative decomposition based on a first-order VAR tends to overstate the importance of predictability of future interest spreads and exchange rates.

Keywords: exchange rates, currency return predictability, interest rate differentials, variance decomposition, present-value relation, carry trade, uncovered interest rate parity

JEL classification: F31, G12, G15, G17
\end{abstract}




\section{Introduction}

The international finance literature has widely documented the empirical failure of the uncovered interest rate parity (UIP), i.e. the fact that interest rate differentials fail to predict currency returns. Similarly, forward exchange rates are not unbiased predictors of the future spot rate. See, for some examples in the literature, Hansen and Hodrick (1980), Bilson (1981), Meese and Rogoff (1983), Fama (1984), Hodrick (1987) and more recently Engel (1996) and Sarno (2005). The empirical rejection of the UIP is commonly known as the "forward premium puzzle" and it motivates currency speculation strategies that exploit this apparent arbitrage opportunity. The carry trade, one of the most popular strategies, consists of borrowing low-interest-rate currencies and lending high-interest-rate currencies. It has received a great deal of attention in the academic literature for its profitability. ${ }^{1}$

Our paper contributes to this branch of the literature by defining a variance decomposition for both the nominal and real spot exchange rates based on a present-value relation (see, for example, Froot and Ramadorai (2005)). This present-value relation is similar to the widely used decomposition of the dividend yield derived by Campbell and Shiller (1988), although here it is exact and not approximate. According to this dynamic present-value relation, variation in the current spot exchange rate results from variation in future currency returns, future interest rate differentials, and/or the spot exchange rate at some terminal date. Specifically, the current log exchange rate is positively correlated with future multiperiod log interest rate spreads and the exchange rate at some terminal date, and negatively correlated with future log currency returns.

By using this present-value relation we define a variance decomposition for the log exchange rate in which the slopes obtained from long-horizon regressions represent the fraction of the variance of the current exchange rate attributable to interest spread, return, and future exchange rate predictability. This approach is similar to the analysis conducted for the

\footnotetext{
${ }^{1}$ Papers that study this strategy include Lustig and Verdelhan (2007), Brunnermeier, Nagel, and Pedersen (2009), Burnside et al. (2011), Lustig, Roussanov, and Verdelhan (2011), Menkhoff et al. (2012), Barroso and Santa-Clara (2013), Dobrynskaya (2014), and Jurek (2014).
} 
dividend-to-price in Cochrane (2008, 2011), for the book-to-market ratio in Cohen, Polk, and Vuolteenaho (2003), for the earnings yield in both Chen, Da, and Priestley (2012) and Maio and $\mathrm{Xu}$ (2014), or the net payout yield in Larrain and Yogo (2008).

We estimate a term-structure of variance decompositions in order to account for the different predictability patterns at short and long forecasting horizons. We use seven currencies in the analysis - Canadian Dollar (CAD), Swiss Franc (CHF), British Pound (GBP), Japanese Yen (JPY), Swedish Krona (SEK), Danish Krone (DKK), and the Norwegian Krone (NOK) — spanning the period from 1978:07 to 2011:12.

Our results can be summarized as follows. First, what drives the variation in the nominal and real exchange rates at long horizons is return predictability. Specifically, at the 120month horizon the return slopes vary between -0.74 (SEK) and -1.59 (DKK) in the analysis with nominal exchange rates, which means that the shares of return predictability over the variance of the exchange rate are as large as 159\%. Second, at shorter horizons (until 40 months ahead), the dominant source of variation tends to be the predictability of the future spot rate. This is especially notable in the cases of JPY and CHF, the two currencies typically associated with the short-side of the carry trade strategy. ${ }^{2}$ Third, predictability about future interest rate differentials plays a rather marginal role in driving the current exchange rate. Specifically, at long horizons, the interest differential coefficients have the wrong sign (negative) in the cases of CHF, GBP, JPY, and DKK. For the remaining currencies, the weights associated with interest rate spread predictability vary between $6 \%$ (NOK) and $37 \%$ (CAD) at the 120-month horizon. Fourth, there exists more return predictability and less interest spread and exchange rate predictability in the case of real exchange rates compared to nominal exchange rates. This is especially notable in the cases of CHF and JPY, in which the share of predictability of future real exchange rate converges much faster to zero than in the decomposition based on nominal exchange rates. Consequently, the shares of return predictability are above $100 \%$ across all seven currencies.

\footnotetext{
${ }^{2}$ See Galati, Heath, and McGuire (2007) for a discussion on carry trade implementation.
} 
Following Cochrane (2008), we estimate an alternative variance decomposition for the log exchange rate based on a first-order VAR. Under this approach the coefficients for future returns, interest rate spreads, and exchange rate at multiple horizons are mechanically related with the one-period corresponding slopes. The results indicate that the VAR-based framework leads in some cases to qualitatively different results than the long-horizon regressions, which means that the VAR does not represent a valid approximation to the predictability relation at multiple horizons. Specifically, the VAR tends to overstate the importance of predictability of future interest spreads and exchange rates from the current exchange rate. This pattern is especially notable in the analysis with some nominal exchange rates (CHF and JPY). Under this approach, at very long horizons, most of the variation in the current nominal exchange rate for Japan and Switzerland is due to predictability about future interest rate differentials, with predictability of future currency returns having a secondary role. These results suggest that imposing a first-order VAR might be too restrictive for understanding predictability patterns at long horizons. ${ }^{3}$

Our work is directly related to the long literature that analyzes predictability of currency returns or exchange rate changes at multiple forecasting horizons. A large portion of this literature has focused on the relation between exchange rates and macro fundamentals, such as nominal money supply and real GDP. Examples include Meese and Rogoff (1983), Mark (1995), Kilian (1999), Mark and Sul (2001), Rapach and Wohar (2002), Groen (2005) and Engel and West (2005). The evidence shows a weak relation between currencies and macro fundamentals, with an overall failure of standard models of exchange rates. Nonetheless Engel, Mark, and West (2007) argue that the forecasting power of these models can still be increased by focusing on panel regressions and long-horizon forecasts. In turn, Della Corte, Sarno, and Tsiakas (2009) evaluate the short-horizon predictive ability of economic fundamentals for exchange rate returns. In related work, several recent papers find evidence that currency returns are exposed to different risk factors. Lustig and Verdelhan (2007) show

\footnotetext{
${ }^{3}$ Maio and $\mathrm{Xu}(2014)$ obtain similar conclusions by conducting a variance decomposition for the aggregate earnings yield.
} 
that excess currency returns are a compensation for consumption growth risk. Volatility risk is the focus of various other studies: Lustig, Roussanov, and Verdelhan (2011) provide empirical evidence that a common risk factor in currency markets is related to changes in global equity market volatility, Menkhoff et al. (2012) consider exposures to a global FX volatility risk factor, and Bakshi and Panayotov (2013) look at both currency volatility and commodity returns. Boudoukh, Richardson, and Whitelaw (2013) revisit the uncovered interest parity and show that past forward interest rate differentials have strong forecasting power for exchange rates. Other papers use variables related with the term structure of bond yields to forecast currency returns (e.g., Clarida and Taylor (1997), Clarida, Sarno, Taylor, and Valente (2003), Diez de los Rios (2009), Ang and Chen (2010), and Chen and Tsang (2013)). In contrast with these studies, Burnside et al. (2011) find no role for standard risk factors in explaining exchange rate dynamics and therefore argue for a peso problem explanation. Brunnermeier, Nagel, and Pedersen (2009) show that high interest rate currencies are exposed to sudden crashes when carry trades unwind, suggesting that abnormal currency returns are a compensation for funding liquidity risk in the presence of financial frictions. Their evidence is supported by the findings in Ferreira Filipe and Suominen (2014), who use stock volatility and crash risk from low interest rate countries as a proxy for funding risk. Lettau, Maggiori, Weber (2014) and Dobrynskaya (2014) argue that, as high interest rate currencies have high market exposures in the bad state, a downside risk model can price the cross-section of currency returns. On the other hand, Jurek (2014) shows that crash risk premia can account for at most one-third of the excess return to currency carry trades. Daniel, Hodrick, and Lu (2014) also study the carry trade in terms of exposure to risk factors and drawdowns distribution, while Mueller, Porchia, and Vedolin (2014) explore the monetary policy effects on currency returns.

We contribute to the literature above by studying the term structure of exchange rate predictability and showing that the current nominal exchange rate captures time variation in both currency risk premia and future spot rate, with the relative weights depending on the 
time horizon considered. Our methodology is in line with the branch of the literature that applies the return decomposition of Campbell and Shiller (1988) in the context of the foreign exchange market. Froot and Ramadorai (2005) employ a decomposition of the real exchange rate into cumulated future real interest differentials (the permanent component) and future expected return innovations (the transitory component). By expressing unexpected currency returns as the difference between cash-flow news and expected return news, their goal is to study the interaction between exchange rates, investor flows, and fundamentals. They find that investor flows are important in understanding transitory elements of currency returns, but not the long-run currency value. More recently, Atanasov (2014) also uses the Campbell and Shiller (1988) decomposition to understand currency returns. She first decomposes the return on the stock market into cash-flow and discount-rate news and then calculates the sensitivities of currency returns to these two components. She finds that the sensitivities to the market returns cash-flow news are significantly related to average excess returns on foreign currency portfolios. More directly related to our paper is the work of Balduzzi and Chiang (2014), who also extend the analysis of Cochrane (2008) to currency returns. However, there are three important differences between our paper and Balduzzi and Chiang (2014). First, we compute a variance decomposition for both the nominal and real exchange rates, while they focus on the real exchange rate. As noted above, in some cases, the predictability results for the nominal and real exchange rates differ significantly. Specifically, there is more return predictability and less interest spread and exchange rate predictability in the case of real exchange rates compared to nominal exchange rates. Second, our benchmark variance decomposition is based on long-horizon regressions while Balduzzi and Chiang (2014) rely on the indirect VAR approach. In fact, one of our major results is that the first-order VAR does not represent a valid approximation to the predictability relations at multiple horizons for some of the currencies. As emphasized above, this is particularly evident in the cases of the nominal exchange rates for CHF and JPY, with the two alternative approaches yielding quite opposite results. Third, we focus on a full term structure of forecasting horizons be- 
tween one and 120 months ahead, whereas Balduzzi and Chiang (2014) compute a variance decomposition exclusively for an infinite horizon based on the VAR. One of our major results is that the predictability from the exchange rate differs substantially with the forecasting horizon: at short horizons there is mainly predictability of the future exchange rate itself. On the other hand, at long horizons there is mainly return predictability, with some currencies (CAD and SEK) also showing some degree of interest spread predictability.

The rest of the paper is organized as follows. Section 2 discusses the methodology. Section 3 describes the data. Section 4 presents the main results based on long-horizon regressions. Section 5 presents the alternative VAR-based variance decomposition. Finally, Section 6 concludes.

\section{Methodology}

Consider the gross return associated with a zero-cost investment strategy in foreign currency,

$$
R_{t+1}=\frac{\frac{S_{t+1}}{S_{t}}\left(1+i_{t+1}^{*}\right)}{1+i_{t+1}}
$$

where $S_{t}$ denotes the spot exchange rate at time $t$ (units of domestic currency per unit of foreign currency), $i_{t+1}$ is the domestic short-term interest rate between $t$ and $t+1$, which is known at the beginning of the period, and $i_{t+1}^{*}$ stands for the foreign interest rate.

By applying logs to the previous identity, we obtain:

$$
r_{t+1}=s_{t+1}-s_{t}+d_{t+1}
$$

where $r_{t+1}$ is the log currency return, $s_{t+1}$ denotes the log exchange rate at the end of $t+1$, and $d_{t+1} \equiv \ln \left(1+i_{t+1}^{*}\right)-\ln \left(1+i_{t+1}\right)$ represents the log interest rate differential.

The previous equation can be interpreted as a difference equation in $s_{t}$. By solving 
forward for $s_{t}$, we obtain the following dynamic decomposition for the log exchange rate:

$$
s_{t}=\sum_{j=1}^{K} d_{t+j}-\sum_{j=1}^{K} r_{t+j}+s_{t+K} .
$$

According to this dynamic present value relation, variation in the current log spot exchange rate results from variation in future currency log returns, future log interest rate differentials, or the log exchange rate at some future date. Specifically, the current log exchange rate is positively correlated with future multiperiod log interest rate spreads and the exchange rate at some terminal date, and negatively correlated with future log currency returns. Hence, this relation represents a valid benchmark to analyse predictability in currency markets, and is similar to the Campbell and Shiller (1988) decomposition associated with the log dividend-to-price ratio, except the fact that it holds exactly rather than approximately.

As shown in Appendix A, by employing the present-value relation above we can define a variance decomposition for the log exchange rate,

$$
1=b_{d}^{K}-b_{r}^{K}+b_{s}^{K},
$$

where $b_{d}^{K}, b_{r}^{K}$, and $b_{s}^{K}$ represent the fraction of the variance of the current exchange rate attributable to interest spread, return, and future exchange rate predictability, respectively. ${ }^{4}$ Estimating a term-structure of variance decompositions, that is one decomposition for each forecasting horizon $K$, enables us to account for the different predictability patterns at short and long horizons. Under this variance decomposition, if the shares associated with the predictability of interest rate spreads and future exchange rates are small or close to zero, this reinforces the evidence of return predictability from the exchange rate since the three slopes have to sum to one. In order words, since the nominal exchange rate varies over time, there must be at least one of these three sources of predictability in driving the exchange

\footnotetext{
${ }^{4}$ In contract to the variance decomposition for the dividend-to-price ratio (or alternative stock market ratios), which holds approximately, this variance decomposition holds exactly.
} 
rate. Cochrane $(2008,2011)$ and Maio and Xu (2014) use similar variance decompositions for the market dividend yield and earnings yield, respectively, while Maio and Santa-Clara (2013) apply a variance decomposition for portfolio dividend yields.

The predictive coefficients above are obtained from the following long-horizon forecasting regressions:

$$
\begin{gathered}
\sum_{j=1}^{K} d_{t+j}=a_{d}^{K}+b_{d}^{K} s_{t}+\varepsilon_{t+K}^{d}, \\
\sum_{j=1}^{K} r_{t+j}=a_{r}^{K}+b_{r}^{K} s_{t}+\varepsilon_{t+K}^{r}, \\
s_{t+K}=a_{s}^{K}+b_{s}^{K} s_{t}+\varepsilon_{t+K}^{s} .
\end{gathered}
$$

The $t$-statistics associated with the predictive slopes are based on Newey and West (1987) standard errors with $K$ lags.

Following Cochrane (2008), an alternative approach to study predictability uses a restricted first-order VAR,

$$
\begin{aligned}
& r_{t+1}=a_{r}+b_{r} s_{t}+\varepsilon_{t+1}^{r}, \\
& d_{t+1}=a_{d}+b_{d} s_{t}+\varepsilon_{t+1}^{d}, \\
& s_{t+1}=a_{s}+\phi s_{t}+\varepsilon_{t+1}^{s},
\end{aligned}
$$

to obtain the following variance decomposition for $s$ :

$$
\begin{aligned}
1 & =b_{d}^{K}-b_{r}^{K}+b_{s}^{K}, \\
b_{d}^{K} & \equiv \frac{b_{d}\left(1-\phi^{K}\right)}{1-\phi}, \\
b_{r}^{K} & \equiv \frac{b_{r}\left(1-\phi^{K}\right)}{1-\phi}, \\
b_{s}^{K} & \equiv \phi^{K} .
\end{aligned}
$$


The full derivation of this alternative variance decomposition is shown in Appendix B. The $t$-statistics for the predictive coefficients, $b_{d}^{K}, b_{r}^{K}, b_{s}^{K}$, are based on the $t$-statistics associated with the VAR slopes above by using the Delta method. The standard error formulas are presented in Appendix B.

In the very long-run $(K \rightarrow \infty)$, the VAR-based variance decomposition is given by

$$
\begin{aligned}
1 & =b_{d}^{l r}-b_{r}^{l r}, \\
b_{d}^{l r} & \equiv \frac{b_{d}}{1-\phi}, \\
b_{r}^{l r} & \equiv \frac{b_{r}}{1-\phi}
\end{aligned}
$$

which stems from the assumption that the share of future exchange rate predictability dies off in the very long-run, $\lim _{K \rightarrow \infty} \phi^{K}=0$.

We also derive a present-value relation for the real exchange rate,

$$
q_{t}=\sum_{j=1}^{K} d_{t+j}-\sum_{j=1}^{K} r_{t+j}+q_{t+K}
$$

where $r_{t+1}$ is the log real currency return, $q_{t+1}$ denotes the log real exchange rate, and $d_{t+1}$ represents the real interest rate differential.

The variance decomposition for the log real exchange rate is given by

$$
1=b_{d}^{K}-b_{r}^{K}+b_{q}^{K}
$$

where $b_{d}^{K}, b_{r}^{K}$, and $b_{q}^{K}$ represent the predictive slopes for future real interest spread spreads, real returns, and real exchange rate. The slopes are obtained from the following long-horizon 
regressions:

$$
\begin{gathered}
\sum_{j=1}^{K} d_{t+j}=a_{d}^{K}+b_{d}^{K} q_{t}+\varepsilon_{t+K}^{d}, \\
\sum_{j=1}^{K} r_{t+j}=a_{r}^{K}+b_{r}^{K} q_{t}+\varepsilon_{t+K}^{r}, \\
q_{t+K}=a_{q}^{K}+b_{q}^{K} q_{t}+\varepsilon_{t+K}^{q} .
\end{gathered}
$$

The VAR-based variance decomposition for the log real exchange rate is given by

$$
\begin{aligned}
1 & =b_{d}^{K}-b_{r}^{K}+b_{q}^{K}, \\
b_{d}^{K} & \equiv \frac{b_{d}\left(1-\phi^{K}\right)}{1-\phi}, \\
b_{r}^{K} & \equiv \frac{b_{r}\left(1-\phi^{K}\right)}{1-\phi}, \\
b_{q}^{K} & \equiv \phi^{K}
\end{aligned}
$$

where the one-period predictive slopes are obtained from the following first-order VAR:

$$
\begin{aligned}
& r_{t+1}=a_{r}+b_{r} q_{t}+\varepsilon_{t+1}^{r}, \\
& d_{t+1}=a_{d}+b_{d} q_{t}+\varepsilon_{t+1}^{d}, \\
& q_{t+1}=a_{q}+\phi q_{t}+\varepsilon_{t+1}^{q} .
\end{aligned}
$$

By allowing $K \rightarrow \infty$ and imposing the terminal condition $\lim _{K \rightarrow \infty} q_{t+K}=0$ (that is, Purchased Power Parity (PPP) holds in the long-run), we obtain a long-run dynamic decomposition for $q$,

$$
q_{t}=\sum_{j=1}^{\infty} d_{t+j}-\sum_{j=1}^{\infty} r_{t+j}
$$

which is the relation derived in Froot and Ramadorai (2005) and Engel (2012). 
The corresponding long-run VAR-based variance decomposition for $q$ is given by

$$
\begin{aligned}
1 & =b_{d}^{l r}-b_{r}^{l r}, \\
b_{d}^{l r} & \equiv \frac{b_{d}}{1-\phi}, \\
b_{r}^{l r} & \equiv \frac{b_{r}}{1-\phi} .
\end{aligned}
$$

\section{Data and variables}

We use monthly data on spot and one-month forward exchange rates (amounts of U.S. dollars per unit of foreign currency) associated with seven currencies - Canadian Dollar (CAD), Swiss Franc (CHF), British Pound (GBP), Japanese Yen (JPY), Swedish Krona (SEK), Danish Krone (DKK), and the Norwegian Krone (NOK). The sample is from 1978:07 to 2011:12. ${ }^{5}$ The exchange data are from Datastream.

The log interest rate spread is computed as

$$
d_{t+1}=s_{t}-f_{t+1}
$$

where $f_{t+1}$ is the log forward exchange rate. Based on the data for $s$ and $d$, the monthly currency log returns are computed from equation (2) above.

The log real exchange rate is given by

$$
q_{t+1}=s_{t+1}+\ln \left(\frac{\Pi_{t+1}^{*}}{\Pi_{t+1}}\right)
$$

where $\Pi^{*}$ and $\Pi$ denote the price indices for the foreign country and U.S., respectively. The price index data are obtained from the OECD/MEI database.

\footnotetext{
${ }^{5}$ The starting date is constrained by the availability on the forward exchange rate data.
} 
The differential of real interest rates is computed as

$$
d_{t+1}=s_{t}-f_{t+1}-\pi_{t+1}^{*}+\pi_{t+1}
$$

where $\pi_{t+1}^{*}$ and $\pi_{t+1}$ are the inflation rates for the foreign country and U.S., respectively, with $\pi_{t+1}=\ln \left(\Pi_{t+1} / \Pi_{t}\right)$.

The log real currency return is then obtained from

$$
r_{t+1}=q_{t+1}-q_{t}+d_{t+1}
$$

which corresponds to the nominal return since both represent excess returns.

The descriptive statistics for the nominal log exchange rate $(s)$, log return $(r)$, and $\log$ interest rate differential $(d)$ are shown in Table 1. Currency returns are significantly more volatile than the corresponding interest rate differentials across all currencies. On the other hand, the interest rate spreads are quite persistent variables, as opposed to currency returns with autocorrelation coefficients around zero. Yet, the most persistent series are the log exchange rates with autoregressive coefficients above 0.97 in all cases (above 0.99 in the cases of CHF and JPY). $r$ and $d$ are (weakly) positively correlated when the currencies are CHF, GBP, JPY, and DKK. On the other hand, $d$ and $s$ are positively correlated in the cases of CHF and JPY, and negatively correlated in the case of NOK.

The descriptive statistics for the real variables are presented in Table 2, which is similar to Table 1 . We can see that the real interest rate differentials are significantly more volatile and less persistent than the nominal counterparts. The highest autocorrelations are only slightly above 0.30 (for CHF and DKK). On the other hand, the log real exchange rates show similar persistence to the nominal exchange rates, with the exceptions of CHF and JPY in which the real exchange rates are less persistent than the corresponding nominal variables. The three variables in the predictive system are not significantly correlated as most pairwise correlations are below 0.20. The largest correlation occurs between $r$ and $q$ in 
the case of CHF (0.27). Thus, the real variables are less correlated among themselves than the nominal counterparts.

\section{Benchmark variance decomposition}

In this section, we compute the benchmark variance decomposition for the log exchange rate presented in Section 2 .

\subsection{Predictability from nominal exchange rates}

We start by computing the variance decomposition associated with the log nominal exchange rate based on long-horizon regressions. The term-structure of predictive slopes is shown in Figure 1, and the associated $t$-statistics are shown in Figure 2. Due to large disparity in scale, we do not graph the $t$-ratios for the slopes in the regressions for the future exchange rate.

For all seven currencies, at long horizons the bulk of variation in the current log exchange rate is predictability of future currency returns. However, there are some significant differences in magnitudes of the slopes across currencies: at $K=120$, the return slopes vary between -0.74 (SEK) and -1.59 (DKK). This means that the share of return predictability

over the variance of the current exchange rate varies between $74 \%$ and $159 \%$. Across all currencies the return slopes are statistically significant at the $5 \%$ level at most forecasting horizons. The exceptions are the cases of CAD, CHF, and JPY in which the slopes are not significant at short and intermediate horizons.

At long horizons, the interest differential coefficients have the wrong sign (negative) in the cases of CHF, GBP, JPY, and DKK, thus explaining the very negative return slopes for these currencies (below -1). For the remaining currencies, the weights associated with interest rate spread predictability vary between $6 \%(\mathrm{NOK})$ and $37 \%(\mathrm{CAD})$ at the 120 -month horizon. Yet, only in the case of CAD is the interest spread slope statistically significant at the $5 \%$ 
level. At intermediate horizons, there is also some degree of interest spread predictability (with the right sign) when the currencies are CAD, CHF, and SEK. However, only in the case of CAD are these estimates statistically significant. At short horizons, the interest coefficients associated with CHF and JPY are positive and statistically significant, yet, the magnitudes are quite small, especially in the case of JPY.

The predictive slopes at long-horizons for the future exchange rate have the wrong sign (negative) in the cases of CAD, CHF, DKK, and NOK. For the remaining three currencies these coefficients vary between 0.06 (SEK) and 0.15 (JPY) at $K=120$, although none of these estimates are significant. At short horizons (until 40 months ahead), the dominant source of variation in the current exchange rate tends to be predictability of the future exchange rate itself. This is especially notable in the cases of CHF and more remarkably JPY, where the coefficients for future $s$ converge to zero rather slowly. This result is a consequence of the fact that these exchange rates are the more persistent ones, as shown in Section 3. The currencies in which the slopes for future $s$ converge faster to zero are GBP, SEK, and NOK.

\subsection{Predictability from real exchange rates}

The variance decomposition associated with the real exchange rate is presented in Figures 3 and 4, which are similar to Figures 1 and 2, respectively. At long horizons, the bulk of variation in the current real exchange rate is currency return predictability, with interest rate spread predictability assuming a very marginal role for most currencies. Specifically, at $K=120$, the return slopes are below -1 for all currencies, varying between -1.21 for GBP and -1.74 for DKK. This means that the predictability of future returns explains more than $100 \%$ of the variation in the current real exchange rate, and the share of return predictability is larger than in the benchmark case associated with nominal exchange rates. Furthermore, only in the case of CAD do the long-horizon interest rate spread coefficients have the correct sign, representing around $30 \%$ of the variation in $q$ at $K=120$. Additionally, the long- 
horizon slopes for future $q$ also have the wrong sign (negative) across most currencies, the exception being GBP, which tend to reinforce the very negative return slopes.

With the exception of CAD, interest spread predictability also does not play a significant role at short and intermediate forecasting horizons. For some currencies (CHF, SEK, and DKK) the interest slopes are positive at those horizons, but the magnitudes are rather small. Moreover, with the exception of very short horizons, these coefficient estimates are not statistically significant at the $5 \%$ level. On the other hand, the return slopes are statistically significant at most horizons across all seven currencies. The main exceptions are the cases of CAD, CHF, JPY, and DKK at short horizons.

Similarly to the benchmark decomposition based on nominal exchange rates, predictability of future exchanges rates at short-horizons drives the variation of the current exchange rate. Nevertheless, the coefficients associated with future real exchange rates tend to converge faster to zero than in the benchmark case based on nominal variables, especially when the currencies are CHF and JPY. This is a consequence of the lower persistence of the real exchange rates for these two currencies compared to the corresponding nominal exchange rates, as shown in the previous Section. Overall, the results of this subsection indicate that there is more (less) return (interest spread and exchange rate) predictability than in the benchmark variance decomposition associated with the nominal exchange rate.

In sum, we can summarize the results of this section as follows: First, what drives the variation in the nominal and real exchange rates at long horizons is return predictability. Second, at short horizons, there is mainly predictability about future exchange rates. Third, predictability about future interest rate differentials plays a rather marginal role in driving the current exchange rate. Fourth, there exists more return predictability and less interest spread and exchange rate predictability in the case of real exchange rates compared to nominal exchange rates. This is especially notable in the cases of CHF and JPY, in which the share of predictability of future real exchange rate converges much faster to zero than in the decomposition based on nominal exchange rates. 


\section{$5 \quad$ VAR-based predictability}

In this section, we estimate the VAR-based variance decomposition for the nominal and real exchange rates.

\subsection{Predictability from nominal exchange rates}

We start with the analysis for nominal exchange rates. The term-structure of predictive coefficients based on the first-order VAR is displayed in Figure 5, and the respective $t$ statistics are presented in Figure 6. The first-order VAR estimates are presented in Table 3.

At long horizons, for most currencies it turns out that return predictability is the main driver of variation in the current log exchange rate. The exceptions are CHF and JPY. In the case of JPY, even at $K=120$, it happens that most of the variation in the spot exchange rate is due to predictability of the future exchange rate. This result should be a consequence of the very high persistence of the log exchange rate for this currency, as noted in the previous sections. In the case of $\mathrm{CHF}$, both interest spread and future exchange rate predictability at long horizons have similar weights in driving the current exchange rate. For these two currencies, as well as for CAD, the return slopes are not significant at any horizon, whereas for the remaining four currencies the return coefficients are significant at most forecasting horizons (the exception is DKK at short horizons).

In contrast to the benchmark variance decomposition based on the long-horizon regressions, the slopes associated with $d$ have the correct sign for most currencies. The exceptions are GBP and NOK for which the respective slopes are negative at all horizons in result of negative one-month ahead slopes from the VAR (statistically significant in the case of NOK). In the cases of JPY, and especially CHF, long-horizon interest spread predictability represents a significant fraction of the variation in the exchange rate. Moreover, for these

two currencies the interest slopes are statistically significant at all forecasting horizons. This 
pattern is better illustrated by the long-run (infinite horizon) coefficients in Table 3: the long-run return coefficients vary between -0.33 (CHF and JPY) and -1.21 (NOK), while the long-run interest differential slopes vary between -0.21 (NOK) and 0.67 (CHF and JPY). Therefore, for both CHF and JPY, in the very long-run what drives variation in the current exchange rate under the VAR framework is predictability of future interest rate spreads rather than predictability about future returns. Still, the standard errors associated with the long-run estimates for these two currencies are large: while we cannot reject the null that the interest spread slopes are equal to one in both cases (that is, the null that all the variation in the exchange rate is driven by long-run interest spread predictability), we also cannot reject the null that these slopes are equal to zero (that is, the null that all the variation in the exchange rate is driven by long-run return predictability).

At short forecasting horizons, the key driving force of the exchange rate is predictability of the future exchange rate, and as noted above, this pattern is particularly strong when the currencies are CHF and JPY. Even at intermediate horizons (between 40 and 60 months), the shares of exchange rate predictability are economically significant for most currencies (above $30 \%$ ). Hence, in comparison to the benchmark variance decomposition, the coefficients associated with future $s$ decay much slowly to zero. This is a consequence of the fact that the multi-period VAR-based slopes are mecanically related with the one-month VAR slopes, which have high magnitudes across all currencies.

Therefore, the results from this subsection represent evidence that in the VAR-based variance decomposition there is more predictability associated with $d$ and future $s$ than in the decomposition based on long-horizon regressions. Specifically, for some currencies (especially CHF and JPY), the VAR and long-horizon regressions provide significantly different patterns of predictability at long horizons. In other words, for these currencies the long-run dynamics between the exchange rate and returns/interest differentials are not conveniently captured by the first-order VAR. ${ }^{6}$

\footnotetext{
${ }^{6}$ In a recent paper, Maio and Xu (2014) also show that the first-order VAR does not provide a good approximation for the long-horizon predictability patterns associated with the aggregate earnings yield.
} 


\subsection{Predictability from real exchange rates}

The VAR-based variance decomposition for the real exchange rates is displayed in Figures 7 and 8. The first-order VAR estimates are presented in Table 4. The long-run (infinite horizon) return slopes vary between $-0.63(\mathrm{CAD})$ and -0.90 (GBP), and for all seven currencies we reject the null that $b_{r}^{l r}=0$ at the $1 \%$ level. On the other hand, the range for the long-run interest differential coefficients is between 0.10 (GBP) and 0.37 (CAD). Hence, in contrast to the VAR-based variance decomposition for the nominal exchange rate, the key driver for changes in $q$ is return predictability at very long horizons across all currencies. The difference in results is especially notable in the cases of CHF and JPY, for which interest spread long-run predictability plays a dominant role in explaining the nominal exchange rate for these two currencies. In fact, only in one case (DKK), we reject the null that $b_{d}^{l r}=0$, although marginally so (10\% level).

By looking at the term structure of predictive slopes it turns out that return predictability is the key component of variation in $q$ at intermediate and long horizons across most currencies. Nevertheless, the coefficients associate with interest spreads show relevant magnitudes when the currencies are CAD, CHF, SEK, and DKK, with estimates between $20 \%$ and $30 \%$. Moreover, these interest spread slope estimates are significant at most horizons at the $5 \%$ level, with the exception of SEK at long horizons (although still showing significance at the $10 \%$ level). On the other hand, at short horizons the major driving force of variation in $q$ is predictability of the future real exchange rate, similarly to the VAR-based decomposition for the nominal exchange rates.

By comparing with the benchmark variance decomposition based on direct regressions analysed in Section 4, two main conclusions emerge. First, there is less return and more interest spread predictability under the VAR decomposition across all currencies. For example, this is illustrated by the fact that the interest spread coefficients have the correct sign (positive) for all currencies, in contrast to the benchmark decomposition. This is a consequence of the fact that the one-month slopes associated with $d$ are positive in all cases 
and are statistically significant for most currencies (the exception is GBP). Second, there is a larger amount of predictability of future $q$ under the VAR framework at short and middle horizons. Specifically, the slopes for future $q$ converge to zero on a slower basis than in the case of long-horizon regressions.

Overall, the results of this section indicate that the VAR-based framework leads in some cases to qualitatively different results than the long-horizon regressions, which means that the VAR does not represent a valid approximation to the predictability relation at multiple horizons. Specifically, the VAR tends to overstate the importance of predictability of future interest spreads and exchange rates from the current exchange rate. This pattern is especially notable in the analysis with some nominal exchange rates (CHF and JPY).

\section{Conclusion}

We specify a variance decomposition for both the nominal and real spot exchange rates based on a present-value relation. According to this dynamic present-value relation, the current log exchange rate is positively correlated with future multiperiod log interest rate spreads and the exchange rate at some terminal date, and negatively correlated with future log currency returns. By using this present-value relation, we define a variance decomposition for the log exchange rate in which the slopes obtained from long-horizon regressions represent the fraction of the variance of the current exchange rate attributable to interest spread, return, and future exchange rate predictability.

We estimate a term-structure of variance decompositions in order to account for the different predictability patterns at short and long forecasting horizons. We use seven currencies in the analysis - Canadian Dollar (CAD), Swiss Franc (CHF), British Pound (GBP), Japanese Yen (JPY), Swedish Krona (SEK), Danish Krone (DKK), and the Norwegian Krone (NOK) — spanning the period from 1978:07 to 2011:12.

Our results can be summarized as follows. First, what drives the variation in the nominal 
and real exchange rates at long horizons is return predictability. Specifically, at the 120month horizon the return slopes vary between -0.74 (SEK) and -1.59 (DKK) in the analysis with nominal exchange rates, which means that the shares of return predictability over the variance of the exchange rate are as large as 159\%. Second, at shorter horizons (until 40 months ahead), the dominant source of variation tends to be the predictability of the future spot rate. This is especially notable in the cases of JPY and CHF, the two currencies typically associated with the short-side of the carry trade strategy. Third, predictability about future interest rate differentials plays a rather marginal role in driving the current exchange rate. Specifically, at long horizons, the interest differential coefficients have the wrong sign (negative) in the cases of CHF, GBP, JPY, and DKK. Fourth, there exists more return predictability and less interest spread and exchange rate predictability in the case of real exchange rates compared to nominal exchange rates. This is especially notable in the cases of CHF and JPY, in which the share of predictability of future real exchange rate converges much faster to zero than in the decomposition based on nominal exchange rates.

Following Cochrane (2008), we estimate an alternative variance decomposition for the log exchange rate based on a first-order VAR. The results indicate that the VAR-based framework leads in some cases to qualitatively different results than the long-horizon regressions, which means that the VAR does not represent a valid approximation to the predictability relation at multiple horizons. Specifically, the VAR tends to overstate the importance of predictability of future interest spreads and exchange rates from the current exchange rate. This pattern is especially notable in the analysis with some nominal exchange rates (CHF and JPY). These results suggest that imposing a first-order VAR might be too restrictive for understanding predictability patterns at long horizons. 


\section{References}

Ang, A., and J. Chen, 2010, Yield curve predictors of foreign exchange returns, Working paper, Columbia University.

Atanasov, V., 2014, Foreign currency returns and systematic risks, Journal of Financial and Quantitative Analysis, forthcoming.

Bakshi, G., and G. Panayotov, 2013, Predictability of currency carry trades and asset pricing implications, Journal of Financial Economics 110, 139-163.

Balduzzi, P., and I. E. Chiang, 2014, Real exchange rates and currency risk premia, Working paper, Boston College.

Barroso, P., and P. Santa-Clara, 2013, Beyond the carry trade: Optimal currency portfolios, Journal of Financial and Quantitative Analysis, forthcoming.

Bilson, J., 1981, Speculative efficiency, Journal of Business 54, 435-451.

Boudoukh, J., M. Richardson, and R. Whitelaw, 2013, New evidence on the forward premium puzzle, Journal of Financial and Quantitative Analysis, forthcoming.

Brunnermeier, M., S. Nagel, and L. Pedersen, 2009, Carry trades and currency crashes, NBER Macroeconomics Annual 23, 313-347.

Burnside, C., M. Eichenbaum, I. Kleshchelski, and S. Rebelo, 2011, Do peso problems explain the returns to the carry trade? Review of Financial Studies 24, 853-891.

Campbell, J., and R. Shiller, 1988, The dividend price ratio and expectations of future dividends and discount factors, Review of Financial Studies 1, 195-228.

Chen, L., Z. Da, and R. Priestley, 2012, Dividend smoothing and predictability, Management Science 58, 1834-1853.

Chen, Y., and K. Tsang, 2013, What does the yield curve tell us about exchange rate predictability, Review of Economics and Statistics 95, 185-205. 
Clarida, R., L. Sarno, M. Taylor, and G. Valente, 2003, The out-of-sample success of term structure models as exchange rate predictors: a step beyond, Journal of International Economics 60, 61-83.

Clarida, R., and M. Taylor, 1997, The term structure of forward exchange premiums and the forecastability of spot exchange rates: Correcting the errors, Review of Economics and Statistics 79, 353-361.

Cochrane, J., 2008, The dog that did not bark: A defense of return predictability, Review of Financial Studies 21, 1533-1575.

Cochrane, J., 2011, Presidential address: Discount rates, Journal of Finance 66, 1047-1108.

Cohen, R., C. Polk, and T. Vuolteenaho, 2003, The value spread, Journal of Finance 58, 609-641.

Daniel, K., J. Hodrick, and Z. Lu, 2014, The carry trade: risks and drawdowns, Working paper, Columbia Business School.

Della Corte, P., L. Sarno, and I. Tsiakas, 2009, An economic evaluation of empirical exchange rate models, Review of Financial Studies 22, 3491-3530.

Diez de los Rios, A., 2009, Can affine term structure models help us predict exchange rates? Journal of Money, Credit and Banking 41, 755-766.

Dobrynskaya, V., 2014, Downside market risk of carry trades, Review of Finance 18, 18851913.

Engel, C., 1996, The forward discount anomaly and the risk premium: A survey of recent evidence, Journal of Empirical Finance 3, 123-192.

Engel, C., 2012, The real exchange rate, real interest rates, and the risk premium, Working paper, University of Wisconsin.

Engel, C., N. Mark, and K. West, 2007, Exchange rate models are not as bad as you think, NBER Macroeconomics Annual 22, 381-441. 
Engel, C., and K. West, 2005, Exchange rates and fundamentals, Journal of Political Economy $113,485-517$.

Fama, E., 1984, Forward and spot exchange rates, Journal of Monetary Economics 14, 319338.

Ferreira Filipe, S., and M. Suominen, 2014, Currency carry trades and funding risk, Working paper, Luxembourg Schhol of Finance.

Froot, K., and T. Ramadorai, 2005, Currency returns, intrinsic value, and institutionalinvestor flows, Journal of Finance 60, 1535-1566.

Galati, G., A. Heath, and P. McGuire, 2007, Evidence of carry trade activity, BIS Quarterly Review.

Groen, J., 2005, Exchange rate predictability and monetary fundamentals in a small multicountry panel, journal of Money, Credit and Banking 37, 495-516.

Hansen, L., and R. Hodrick, 1980, Forward exchange rates as optimal predictors of future spot rates: An econometric analysis, Journal of Political Economy 88, 829-853.

Hodrick, R., 1987, The empirical evidence on the efficiency of forward and futures foreign exchange markets, London: Harwood Academic Publishers.

Jurek, J., 2014, Crash-neutral currency carry trades, Journal of Financial Economics 113, $325-347$.

Kilian, L., 1999, Exchange rates and monetary fundamentals: What do we learn from longhorizon regressions? Journal of Applied Econometrics 14, 491-510.

Larrain, B., and M. Yogo, 2008, Does firm value move too much to be justified by subsequent changes in cash flow? Journal of Financial Economics 87, 200-226.

Lettau, M., M. Maggiori, and M. Weber, 2014, Conditional risk premia in currency markets and other asset classes, Journal of Financial Economics 114, 197-225. 
Lustig, H., N. Roussanov, and A. Verdelhan, 2011, Common risk factors in currency markets, Review of Financials Studies 24, 3731-3777.

Lustig, H., and A. Verdelhan, 2007, The cross section of foreign currency risk premia and consumption growth risk, American Economic Review 97, 89-117.

Maio, P., and P. Santa-Clara, 2013, Dividend yields, dividend growth, and return predictability in the cross-section of stocks, Journal of Financial and Quantitative Analysis, forthcoming.

Maio, P., and D. Xu, 2014, Cash-flow or return predictability at long horizons? The case of earnings yield, Working paper, Hanken School of Economics.

Mark, N., 1995, Exchange rates and fundamentals: evidence on long-horizon predictability, American Economic Review 85, 201-218.

Mark, N., and D. Sul, 2001, Nominal exchange rates and monetary fundamentals: Evidence from a small post-Bretton woods panel, Journal of International Economics 53, 29-52.

Meese, R., and K. Rogoff, 1983, Empirical exchange rate models of the seventies: Do they fit out of sample? Journal of International Economics 14, 3-24.

Menkhoff, L., L. Sarno, M. Schmeling, and A. Schrimpf, 2012, Carry trades and global foregin exchange volatility, Journal of Finance 67, 681-718.

Mueller, P., P. Porchia, and A. Vedolin, 2014, Policy announcements in FX markets, Working paper, London School of Economics.

Newey, W., and K. West, 1987, A simple, positive semi-definite, heteroskedasticity and autocorrelation consistent covariance matrix, Econometrica 55, 703-708.

Rapach, D., and M. Wohar, 2002, Testing the monetary model of exchange rate determination: new evidence from a century of data, Journal of International Economics 58, 359-385. 
Sarno, L., 2005, Viewpoint: Towards a solution to the puzzles in exchange rate economics: where do we stand? Canadian Journal of Economics 38, 673-708. 


\section{A Derivation of the variance decomposition for $s$}

By multiplying both sides of the present-value relation in equation (3) by $s_{t}-\mathrm{E}\left(s_{t}\right)$, and taking unconditional expectations, we obtain the following variance decomposition for $s_{t}$,

$$
\operatorname{Var}\left(s_{t}\right)=\operatorname{Cov}\left(\sum_{j=1}^{K} d_{t+j}, s_{t}\right)-\operatorname{Cov}\left(\sum_{j=1}^{K} r_{t+j}, s_{t}\right)+\operatorname{Cov}\left(s_{t+K}, s_{t}\right)
$$

and by dividing both sides by $\operatorname{Var}\left(s_{t}\right)$, we have,

$$
\begin{gathered}
1=\beta\left(\sum_{j=1}^{K} d_{t+j}, s_{t}\right)-\beta\left(\sum_{j=1}^{K} r_{t+j}, s_{t}\right)+\beta\left(s_{t+K}, s_{t}\right) \Leftrightarrow \\
1=b_{d}^{K}-b_{r}^{K}+b_{s}^{K},
\end{gathered}
$$

where $\beta(y, x)$ denotes the slope from a regression of $y$ on $x$. This expression represents the variance decomposition for $s$ when the predictive slopes are obtained directly from longhorizon regressions. The variance decomposition associated with the real log exchange rate is obtained in a similar way.

\section{B Derivation of the VAR-based variance decomposi- tion for $s$}

Consider the equation derived above,

$$
1=\beta\left(\sum_{j=1}^{K} d_{t+j}, s_{t}\right)-\beta\left(\sum_{j=1}^{K} r_{t+j}, s_{t}\right)+\beta\left(s_{t+K}, s_{t}\right)
$$

and by using the property of regression coefficients, $\beta(y+z, x)=\beta(y, x)+\beta(z, x)$, we have:

$$
1=\sum_{j=1}^{K} \beta\left(d_{t+j}, s_{t}\right)-\sum_{j=1}^{K} \beta\left(r_{t+j}, s_{t}\right)+\beta\left(s_{t+K}, s_{t}\right) .
$$


Under the first-order VAR, we have,

$$
s_{t}=\phi^{1-j} s_{t+j-1}-\sum_{l=1}^{j-1} \phi^{-l}\left(a_{s}+\varepsilon_{t+l}^{s}\right)
$$

and by combining with the VAR equation for currency returns,

$$
r_{t+j}=a_{r}+b_{r} s_{t+j-1}+\varepsilon_{t+j}^{r}
$$

implies the following equation for $r_{t+j}$ :

$$
r_{t+j}=a_{r}+\phi^{j-1} b_{r} s_{t}+\phi^{j-1} b_{r} \sum_{l=1}^{j-1} \phi^{-l}\left(a_{s}+\varepsilon_{t+l}^{s}\right)+\varepsilon_{t+j}^{r} .
$$

Since $\operatorname{Cov}\left(\varepsilon_{t+l}^{s}, s_{t}\right)=0, l>0$ and $\operatorname{Cov}\left(\varepsilon_{t+j}^{r}, s_{t}\right)=0$, by construction, it follows that

$$
\beta\left(r_{t+j}, s_{t}\right)=\phi^{j-1} b_{r}
$$

Similarly, we have,

$$
\beta\left(d_{t+j}, s_{t}\right)=\phi^{j-1} b_{d}
$$

On the other hand, given the expanded expression for $s_{t+K}$,

$$
s_{t+K}=\phi^{K} s_{t}+\phi^{K} \sum_{l=1}^{j-1} \phi^{-l}\left(a_{s}+\varepsilon_{t+l}^{s}\right),
$$

we have

$$
\beta\left(s_{t+K}, s_{t}\right)=\phi^{K},
$$

which leads to

$$
1=\sum_{j=1}^{K} \phi^{j-1} b_{d}-\sum_{j=1}^{K} \phi^{j-1} b_{r}+\phi^{K}
$$


By simplifying the sums above, we obtain the VAR-based variance decomposition associated with $s$ :

$$
\begin{aligned}
1 & =b_{d}^{K}-b_{r}^{K}+b_{s}^{K}, \\
b_{d}^{K} & \equiv \frac{b_{d}\left(1-\phi^{K}\right)}{1-\phi}, \\
b_{r}^{K} & \equiv \frac{b_{r}\left(1-\phi^{K}\right)}{1-\phi}, \\
b_{s}^{K} & \equiv \phi^{K} .
\end{aligned}
$$

To compute the $t$-statistics for the predictive coefficients, $\mathbf{b}^{K} \equiv\left(b_{d}^{K}, b_{r}^{K}, b_{s}^{K}\right)^{\prime}$, we use the Delta method. From the $t$-statistics associated with the VAR slopes, $\mathbf{b} \equiv\left(b_{d}, b_{r}, \phi\right)^{\prime}$, we have:

$$
\operatorname{Var}\left(\mathbf{b}^{K}\right)=\frac{\partial \mathbf{b}^{K}}{\partial \mathbf{b}^{\prime}} \operatorname{Var}(\mathbf{b}) \frac{\partial \mathbf{b}^{K}}{\partial \mathbf{b}} .
$$

The matrix of derivatives is given by

$$
\frac{\partial \mathbf{b}^{K}}{\partial \mathbf{b}^{\prime}} \equiv\left[\begin{array}{ccc}
\frac{\partial b_{d}^{K}}{\partial b_{d}} & \frac{\partial b_{d}^{K}}{\partial b_{r}} & \frac{\partial b_{d}^{K}}{\partial \phi} \\
\frac{\partial b_{r}^{K}}{\partial b_{d}} & \frac{\partial b_{r}^{K}}{\partial b_{r}} & \frac{\partial b_{r}^{K}}{\partial \phi} \\
\frac{\partial b_{s}^{K}}{\partial b_{d}} & \frac{\partial b_{s}^{K}}{\partial b_{r}} & \frac{\partial b_{s}^{K}}{\partial \phi}
\end{array}\right]=\left[\begin{array}{ccc}
\frac{1-\phi^{K}}{1-\phi} & 0 & \frac{-K b_{d} \phi^{K-1}(1-\phi)+b_{d}\left(1-\phi^{K}\right)}{(1-)^{2}} \\
0 & \frac{1-\phi^{K}}{1-\phi} & \frac{-K b_{r} \phi^{K-1}(1-\phi)+b_{r}\left(1-\phi^{K}\right)}{(1-\phi)^{2}} \\
0 & 0 & K \phi^{K-1}
\end{array}\right]
$$


Table 1: Descriptive statistics

This table reports descriptive statistics for the log currency return $(r)$, log interest rate differential $(d)$, and log exchange rate $(s)$. The currencies are the Canadian Dollar (CAD), Swiss Franc (CHF), British Pound (GBP), Japanese Yen (JPY), Swedish Krona (SEK), Danish Krone (DKK), and Norwegian Krone (NOK). $\phi$ designates the first-order autocorrelation coefficient. The columns labeled $r-s$ represent the correlation matrix of the three variables. The sample is 1978:07-2011:12.

\begin{tabular}{|c|c|c|c|c|c|c|c|c|}
\hline & Mean & Stdev. & Min. & Max. & $\phi$ & $r$ & $d$ & $s$ \\
\hline \multicolumn{9}{|c|}{ Panel A (CAD) } \\
\hline$r$ & 0.0008 & 0.0199 & -0.1296 & 0.0902 & -0.050 & 1.00 & 0.11 & 0.11 \\
\hline$d$ & 0.0006 & 0.0014 & -0.0046 & 0.0050 & 0.866 & & 1.00 & 0.09 \\
\hline$s$ & -0.2327 & 0.1197 & -0.4709 & 0.0577 & 0.989 & & & 1.00 \\
\hline \multicolumn{9}{|c|}{ Panel B (CHF) } \\
\hline$r$ & -0.0007 & 0.0368 & -0.1574 & 0.1318 & 0.022 & 1.00 & 0.21 & 0.13 \\
\hline$d$ & -0.0024 & 0.0029 & -0.0128 & 0.0048 & 0.947 & & 1.00 & 0.46 \\
\hline$s$ & -0.3850 & 0.2325 & -1.0496 & 0.2380 & 0.992 & & & 1.00 \\
\hline \multicolumn{9}{|c|}{ Panel C (GBP) } \\
\hline$r$ & 0.0010 & 0.0309 & -0.1269 & 0.1401 & 0.087 & 1.00 & 0.24 & 0.11 \\
\hline$d$ & 0.0015 & 0.0020 & -0.0057 & 0.0075 & 0.911 & & 1.00 & 0.02 \\
\hline 3 & 0.5137 & 0.1344 & 0.0770 & 0.8906 & 0.973 & & & 1.00 \\
\hline \multicolumn{9}{|c|}{ Panel D (JPY) } \\
\hline$r$ & -0.0003 & 0.0344 & -0.1162 & 0.1512 & 0.031 & 1.00 & 0.24 & 0.09 \\
\hline$d$ & -0.0027 & 0.0023 & -0.0115 & 0.0036 & 0.933 & & 1.00 & 0.31 \\
\hline$s$ & -4.9036 & 0.3250 & -5.6240 & -4.3369 & 0.997 & & & 1.00 \\
\hline \multicolumn{9}{|c|}{ Panel E (SEK) } \\
\hline$T$ & 0.0003 & 0.0332 & -0.1661 & 0.0916 & 0.093 & 1.00 & 0.11 & 0.06 \\
\hline$d$ & 0.0013 & 0.0030 & -0.0053 & 0.0363 & 0.713 & & 1.00 & 0.12 \\
\hline$s$ & -1.9390 & 0.2090 & -2.3874 & -1.4166 & 0.982 & & & 1.00 \\
\hline \multicolumn{9}{|c|}{ Panel F (DKK) } \\
\hline$r$ & 0.0010 & 0.0333 & -0.1110 & 0.1115 & 0.026 & 1.00 & 0.19 & 0.09 \\
\hline$d$ & 0.0010 & 0.0029 & -0.0088 & 0.0218 & 0.790 & & 1.00 & 0.03 \\
\hline$s$ & -1.8926 & 0.1932 & -2.4822 & -1.5534 & 0.985 & & & 1.00 \\
\hline \multicolumn{9}{|c|}{ Panel G (NOK) } \\
\hline$r$ & 0.0014 & 0.0318 & -0.1274 & 0.0953 & 0.043 & 1.00 & 0.17 & 0.07 \\
\hline$d$ & 0.0016 & 0.0028 & -0.0110 & 0.0194 & 0.778 & & 1.00 & -0.25 \\
\hline$s$ & -1.8990 & 0.1536 & -2.2581 & -1.5453 & 0.977 & & & 1.00 \\
\hline
\end{tabular}


Table 2: Descriptive statistics (real exchange rate)

This table reports descriptive statistics for the log real currency return $(r)$, $\log$ real interest rate differential $(d)$, and $\log$ real exchange rate $(q)$. The currencies are the Canadian Dollar (CAD), Swiss Franc (CHF), British Pound (GBP), Japanese Yen (JPY), Swedish Krona (SEK), Danish Krone (DKK), and Norwegian Krone (NOK). $\phi$ designates the first-order autocorrelation coefficient. The columns labeled $r-q$ represent the correlation matrix of the three variables. The sample is 1978:07-2011:12.

\begin{tabular}{|c|c|c|c|c|c|c|c|c|}
\hline & Mean & Stdev. & Min. & Max. & $\phi$ & $r$ & $d$ & $q$ \\
\hline \multicolumn{9}{|c|}{ Panel A (CAD) } \\
\hline$r$ & 0.0008 & 0.0199 & -0.1296 & 0.0902 & -0.050 & 1.00 & 0.01 & 0.12 \\
\hline$d$ & 0.0007 & 0.0036 & -0.0167 & 0.0119 & 0.098 & & 1.00 & 0.13 \\
\hline$q$ & -0.2006 & 0.1161 & -0.4627 & 0.0325 & 0.986 & & & 1.00 \\
\hline \multicolumn{9}{|c|}{ Panel B (CHF) } \\
\hline$r$ & -0.0007 & 0.0368 & -0.1574 & 0.1318 & 0.022 & 1.00 & 0.12 & 0.15 \\
\hline$d$ & -0.0010 & 0.0044 & -0.0158 & 0.0125 & 0.315 & & 1.00 & 0.27 \\
\hline$q$ & -0.2527 & 0.1674 & -0.8010 & 0.1359 & 0.977 & & & 1.00 \\
\hline \multicolumn{9}{|c|}{ Panel C (GBP) } \\
\hline$r$ & 0.0010 & 0.0309 & -0.1269 & 0.1401 & 0.087 & 1.00 & 0.08 & 0.14 \\
\hline$d$ & 0.0011 & 0.0055 & -0.0281 & 0.0151 & 0.130 & & 1.00 & 0.05 \\
\hline$q$ & 0.5461 & 0.1180 & 0.0915 & 0.8405 & 0.966 & & & 1.00 \\
\hline \multicolumn{9}{|c|}{ Panel D (JPY) } \\
\hline$r$ & -0.0003 & 0.0344 & -0.1162 & 0.1512 & 0.031 & 1.00 & 0.01 & 0.11 \\
\hline$d$ & -0.0006 & 0.0050 & -0.0236 & 0.0167 & 0.167 & & 1.00 & 0.07 \\
\hline$q$ & -4.6538 & 0.1853 & -5.1062 & -4.1720 & 0.983 & & & 1.00 \\
\hline \multicolumn{9}{|c|}{ Panel E (SEK) } \\
\hline$r$ & 0.0003 & 0.0332 & -0.1661 & 0.0916 & 0.093 & 1.00 & 0.07 & 0.10 \\
\hline$d$ & 0.0010 & 0.0056 & -0.0216 & 0.0247 & 0.230 & & 1.00 & 0.15 \\
\hline$q$ & -1.9189 & 0.1850 & -2.3388 & -1.5031 & 0.981 & & & 1.00 \\
\hline \multicolumn{9}{|c|}{ Panel F (DKK) } \\
\hline$r$ & 0.0010 & 0.0333 & -0.1110 & 0.1115 & 0.026 & 1.00 & 0.10 & 0.12 \\
\hline$d$ & 0.0010 & 0.0052 & -0.0273 & 0.0234 & 0.333 & & 1.00 & 0.18 \\
\hline$q$ & -1.8559 & 0.1729 & -2.3860 & -1.5698 & 0.981 & & & 1.00 \\
\hline \multicolumn{9}{|c|}{ Panel G (NOK) } \\
\hline$r$ & 0.0014 & 0.0318 & -0.1274 & 0.0953 & 0.043 & 1.00 & 0.14 & 0.13 \\
\hline$d$ & 0.0014 & 0.0055 & -0.0266 & 0.0177 & 0.242 & & 1.00 & 0.10 \\
\hline$q$ & -1.8958 & 0.1351 & -2.2915 & -1.6512 & 0.972 & & & 1.00 \\
\hline
\end{tabular}


Table 3: VAR estimates

This table reports the one-month restricted VAR estimation results. The variables in the VAR are the log currency return $(r), \log$ interest rate differential $(d)$, and log exchange rate $(s)$. $b(\phi)$ denote the VAR slopes associated with lagged $s$, while $t$ denotes the respective Newey and West (1987) t-statistics (calculated with one lag). $R^{2}(\%)$ is the coefficient of determination for each equation in the VAR, in $\%$. $b^{l r}$ denote the long-run coefficients (infinite horizon). $t\left(b_{r}^{l r}=0\right)$ and $t\left(b_{r}^{l r}=-1\right)$ denote the t-statistics associated with the null hypotheses $H_{0}: b_{r}^{l r}=0, b_{d}^{l r}=1$ and $H_{0}: b_{r}^{l r}=-1, b_{d}^{l r}=0$, respectively. The currencies are the Canadian Dollar (CAD), Swiss Franc (CHF), British Pound (GBP), Japanese Yen (JPY), Swedish Krona (SEK), Danish Krone (DKK), and Norwegian Krone (NOK). The sample is 1978:07-2011:12.

\begin{tabular}{|c|c|c|c|c|c|c|}
\hline & $b(\phi)$ & $t$ & $R^{2}(\%)$ & $b^{l r}$ & $t\left(b_{r}^{l r}=0\right)$ & $t\left(b_{r}^{l r}=-1\right)$ \\
\hline \multicolumn{7}{|c|}{ Panel A (CAD) } \\
\hline$r$ & -0.010 & -1.05 & 0.35 & -0.905 & -8.69 & 0.91 \\
\hline$d$ & 0.001 & 1.67 & 0.74 & 0.095 & -8.69 & 0.91 \\
\hline$s$ & 0.989 & 106.78 & 97.26 & & & \\
\hline \multicolumn{7}{|c|}{ Panel B (CHF) } \\
\hline$r$ & -0.003 & -0.30 & 0.03 & -0.333 & -0.45 & 0.91 \\
\hline$d$ & 0.005 & 9.09 & 19.16 & 0.667 & -0.45 & 0.91 \\
\hline$s$ & 0.992 & 114.55 & 97.58 & & & \\
\hline \multicolumn{7}{|c|}{ Panel C (GBP) } \\
\hline$r$ & -0.027 & -1.91 & 1.39 & -1.011 & -21.22 & -0.24 \\
\hline$d$ & -0.000 & -0.23 & 0.04 & -0.011 & -21.22 & -0.24 \\
\hline$s$ & 0.973 & 71.48 & 94.92 & & & \\
\hline \multicolumn{7}{|c|}{ Panel D (JPY) } \\
\hline$r$ & -0.001 & -0.18 & 0.01 & -0.331 & -0.26 & 0.52 \\
\hline$d$ & 0.002 & 3.83 & 8.04 & 0.669 & -0.26 & 0.52 \\
\hline$s$ & 0.997 & 181.37 & 98.92 & & & \\
\hline \multicolumn{7}{|c|}{ Panel E (SEK) } \\
\hline$r$ & -0.016 & -2.16 & 1.03 & -0.904 & -12.02 & 1.28 \\
\hline$d$ & 0.002 & 1.54 & 1.40 & 0.096 & -12.02 & 1.28 \\
\hline$s$ & 0.982 & 134.41 & 97.52 & & & \\
\hline \multicolumn{7}{|c|}{ Panel F (DKK) } \\
\hline$r$ & -0.015 & -1.67 & 0.74 & -0.994 & -18.89 & 0.12 \\
\hline$d$ & 0.000 & 0.12 & 0.00 & 0.006 & -18.89 & 0.12 \\
\hline$s$ & 0.985 & 112.25 & 97.12 & & & \\
\hline \multicolumn{7}{|c|}{ Panel G (NOK) } \\
\hline$r$ & -0.028 & -2.68 & 1.78 & -1.207 & -12.98 & -2.22 \\
\hline$d$ & -0.005 & -4.54 & 6.94 & -0.207 & -12.98 & -2.22 \\
\hline$s$ & 0.977 & 96.98 & 95.84 & & & \\
\hline
\end{tabular}


Table 4: VAR estimates: real exchange rate

This table reports the one-month restricted VAR estimation results. The variables in the VAR are the $\log$ currency return $(r)$, log real interest rate differential $(d)$, and log real exchange rate $(q) . \quad b(\phi)$ denote the VAR slopes associated with lagged $q$, while $t$ denotes the respective Newey and West (1987) t-statistics (calculated with one lag). $R^{2}(\%)$ is the coefficient of determination for each equation in the VAR, in $\%$. $b^{l r}$ denote the long-run coefficients (infinite horizon). $t\left(b_{r}^{l r}=0\right)$ and $t\left(b_{r}^{l r}=-1\right)$ denote the t-statistics associated with the null hypotheses $H_{0}: b_{r}^{l r}=0, b_{d}^{l r}=1$ and $H_{0}: b_{r}^{l r}=-1, b_{d}^{l r}=0$, respectively. The currencies are the Canadian Dollar (CAD), Swiss Franc (CHF), British Pound (GBP), Japanese Yen (JPY), Swedish Krona (SEK), Danish Krone (DKK), and Norwegian Krone (NOK). The sample is 1978:07-2011:12.

\begin{tabular}{|c|c|c|c|c|c|c|}
\hline & $b(\phi)$ & $t$ & $R^{2}(\%)$ & $b^{l r}$ & $t\left(b_{r}^{l r}=0\right)$ & $t\left(b_{r}^{l r}=-1\right)$ \\
\hline \multicolumn{7}{|c|}{ Panel A (CAD) } \\
\hline$r$ & -0.009 & -1.06 & 0.27 & -0.630 & -2.71 & 1.59 \\
\hline$d$ & 0.005 & 3.81 & 2.83 & 0.370 & -2.71 & 1.59 \\
\hline$q$ & 0.986 & 116.97 & 96.97 & & & \\
\hline \multicolumn{7}{|c|}{ Panel B (CHF) } \\
\hline$r$ & -0.015 & -1.22 & 0.49 & -0.679 & -3.41 & 1.61 \\
\hline$d$ & 0.007 & 5.07 & 7.51 & 0.321 & -3.41 & 1.61 \\
\hline$q$ & 0.977 & 80.25 & 95.31 & & & \\
\hline \multicolumn{7}{|c|}{ Panel C (GBP) } \\
\hline$r$ & -0.031 & -1.71 & 1.38 & -0.902 & -10.00 & 1.09 \\
\hline$d$ & 0.003 & 1.27 & 0.52 & 0.098 & -10.00 & 1.09 \\
\hline$q$ & 0.966 & 53.88 & 93.24 & & & \\
\hline \multicolumn{7}{|c|}{ Panel D (JPY) } \\
\hline$r$ & -0.015 & -1.41 & 0.62 & -0.850 & -7.04 & 1.24 \\
\hline$d$ & 0.003 & 1.83 & 0.91 & 0.150 & -7.04 & 1.24 \\
\hline$q$ & 0.983 & 95.41 & 96.55 & & & \\
\hline \multicolumn{7}{|c|}{ Panel E (SEK) } \\
\hline$r$ & -0.014 & -1.42 & 0.61 & -0.744 & -4.44 & 1.53 \\
\hline$d$ & 0.005 & $\underline{2.39}$ & 2.59 & 0.256 & -4.44 & 1.53 \\
\hline$q$ & 0.981 & 100.84 & 96.79 & & & \\
\hline \multicolumn{7}{|c|}{ Panel F (DKK) } \\
\hline$r$ & -0.013 & -1.32 & 0.47 & -0.698 & -3.91 & 1.69 \\
\hline$d$ & 0.006 & 3.88 & 3.65 & 0.302 & -3.91 & 1.69 \\
\hline$q$ & 0.981 & 99.99 & 96.33 & & & \\
\hline \multicolumn{7}{|c|}{ Panel G (NOK) } \\
\hline$r$ & -0.023 & -1.87 & 0.96 & -0.839 & -7.88 & 1.51 \\
\hline$d$ & 0.004 & $\underline{2.16}$ & 1.17 & 0.161 & -7.88 & 1.51 \\
\hline$q$ & 0.972 & 81.08 & 94.62 & & & \\
\hline
\end{tabular}




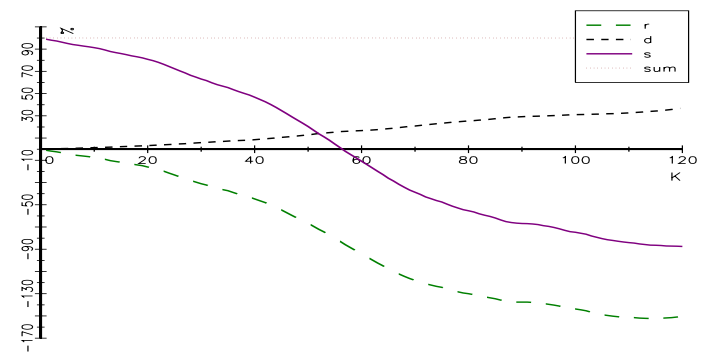

Panel A (CAD)

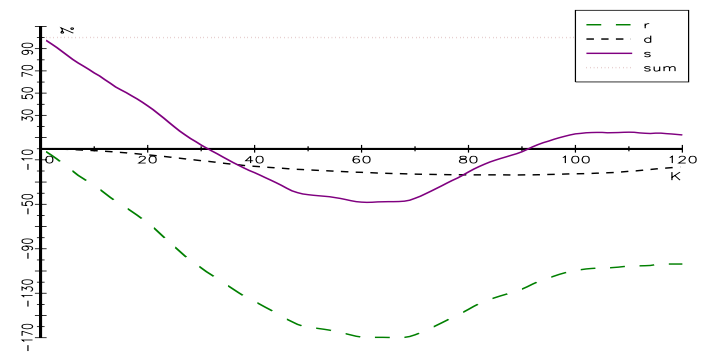

Panel C (GBP)

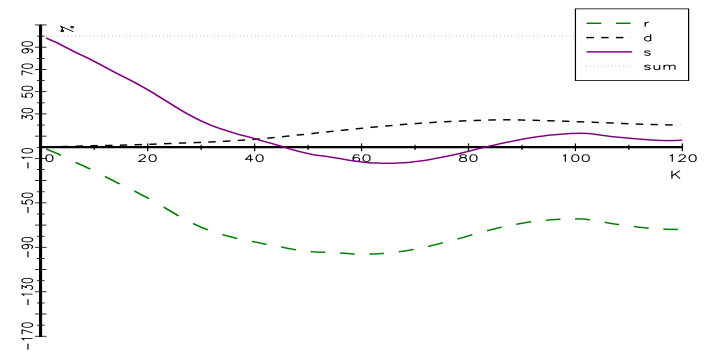

Panel E (SEK)

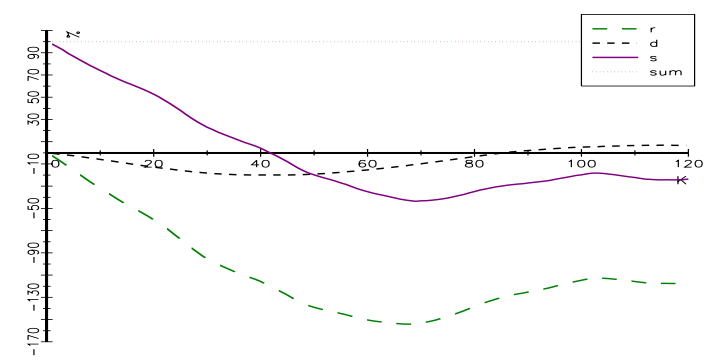

Panel G (NOK)

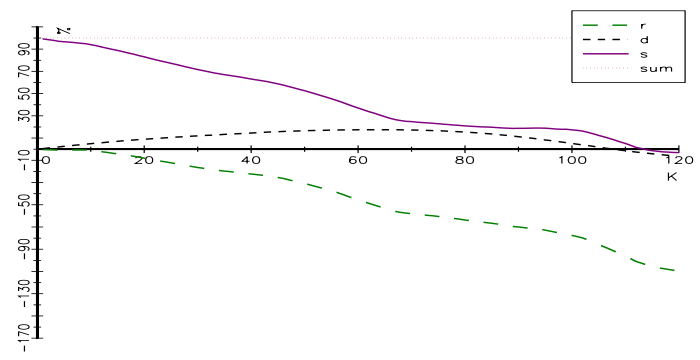

Panel B (CHF)

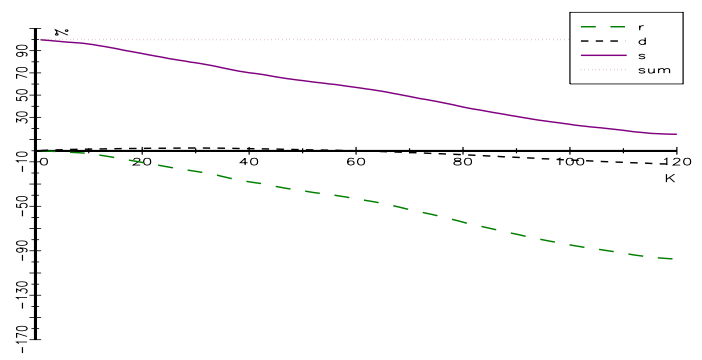

Panel D (JPY)

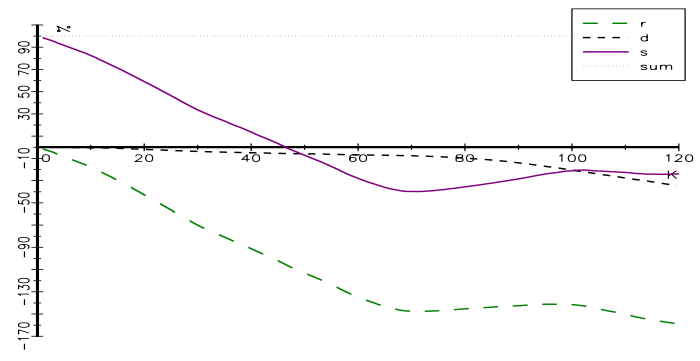

Panel F (DKK)

Figure 1: Term structure of direct long-horizon coefficients

This figure plots the term structure of the direct long-horizon predictive coefficients. The predictive slopes are associated with the log return $(r)$, log interest rate differential $(d)$, and $\log$ spot exchange rate $(s)$. The forecasting variable is the log exchange rate in all three cases. "Sum" denotes the value of the variance decompositign, in \%. The currencies are the Canadian Dollar (CAD), Swiss Franc (CHF), British Pound (GBP), Japanese Yen (JPY), Swedish Krona (SEK), Danish Krone (DKK), and Norwegian Krone (NOK). The long-horizon coefficients are measured in \%, and $K$ represents the number of months ahead. The sample is 1978:07-2011:12. 


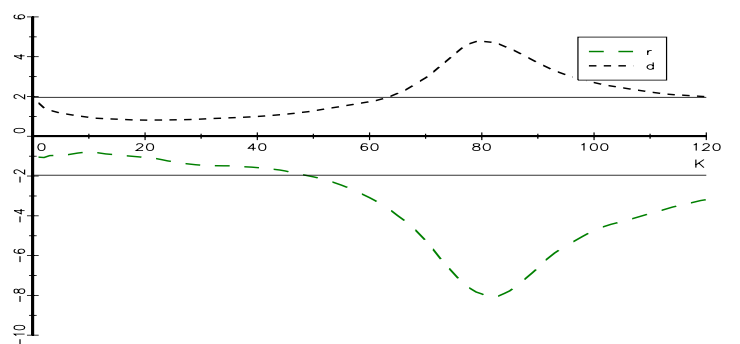

Panel A (CAD)

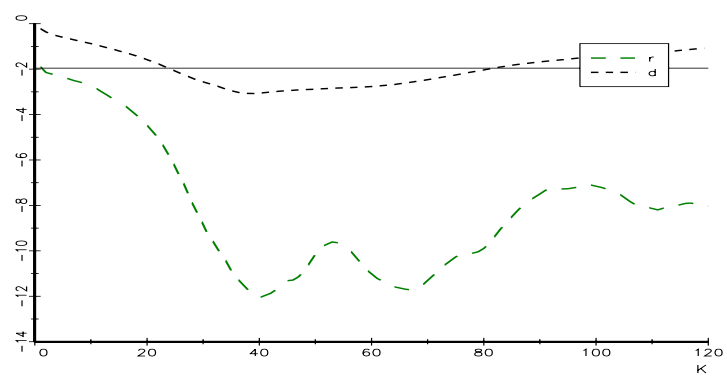

Panel C (GBP)

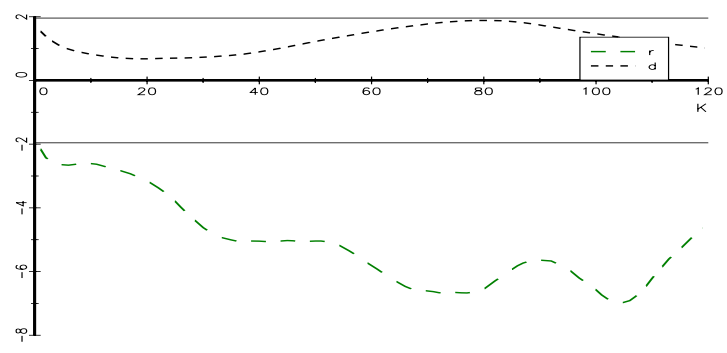

Panel E (SEK)

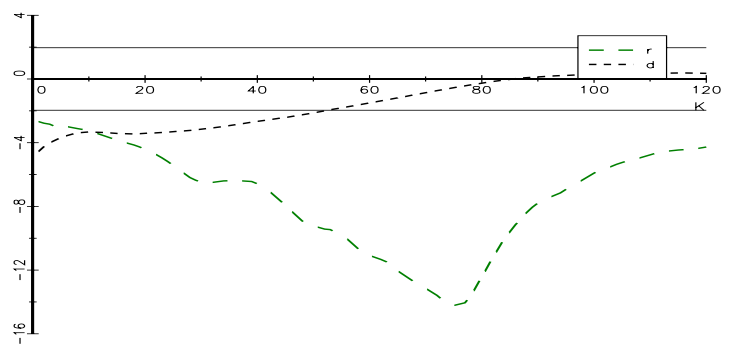

Panel G (NOK)

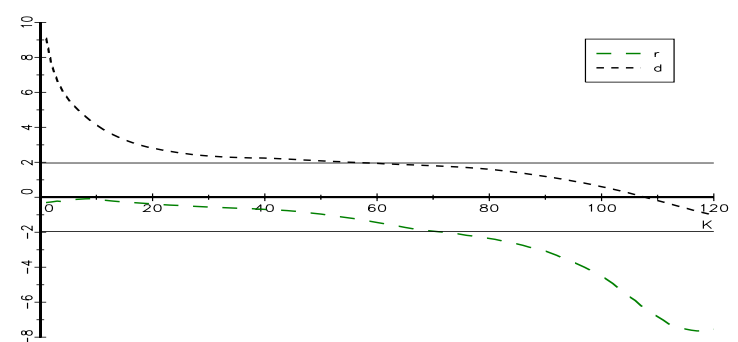

Panel B (CHF)

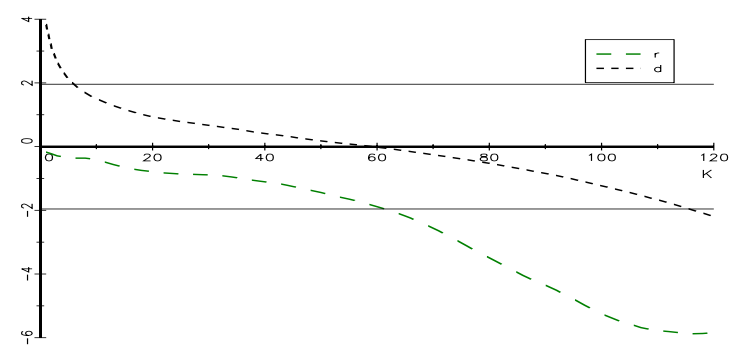

Panel D (JPY)

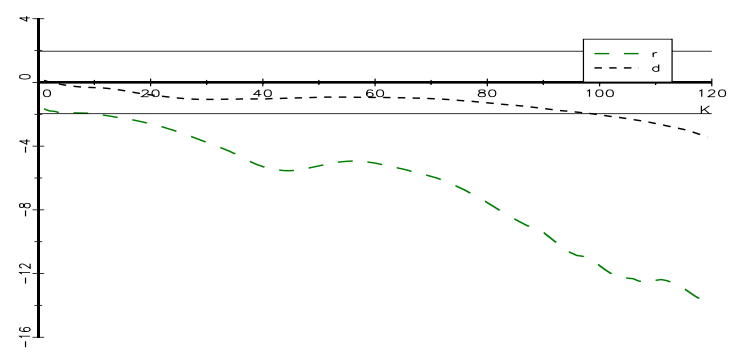

Panel F (DKK)

Figure 2: Term structure of $t$-stats for direct long-horizon coefficients

This figure plots the term structure of the Newey-West t-statistics associated with the direct long-horizon predictive coeffi-
cients. The predictive slopes are associated with the log return $(r)$ and log interest rate differential ( $d$ ). The forecast-
ing variable is the $\log$ exchange rate. The currencies are 3 the Canadian Dollar (CAD), Swiss Franc (CHF), British Pound
(GBP), Japanese Yen (JPY), Swedish Krona (SEK), Danish Krone (DKK), and Norwegian Krone (NOK). The horizontal lines
represent the $5 \%$ critical values $(-1.96,1.96)$. $K$ represents the number of months ahead. The sample is 1978:07-2011:12. 


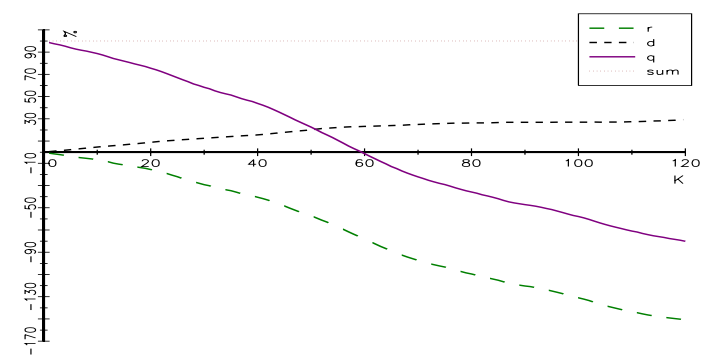

Panel A (CAD)

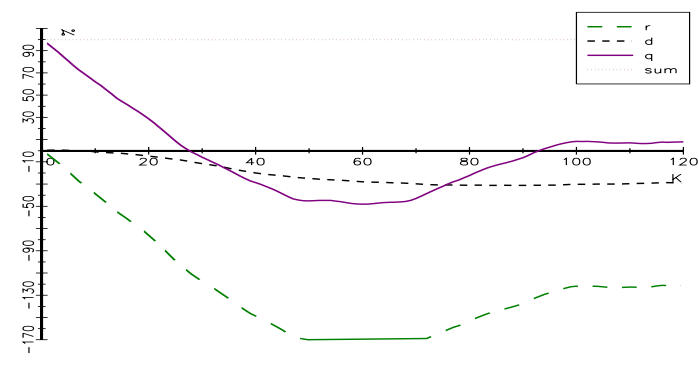

Panel C (GBP)

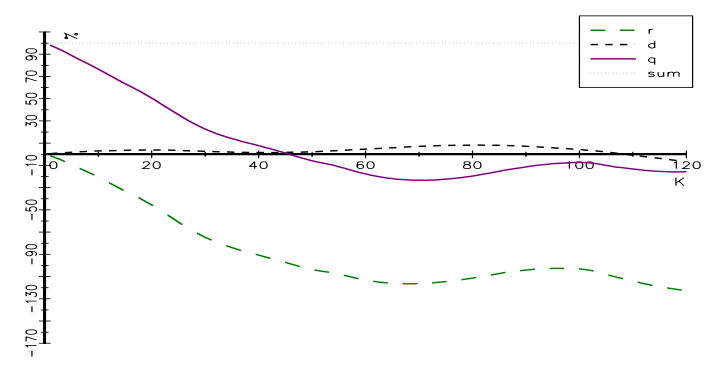

Panel E (SEK)

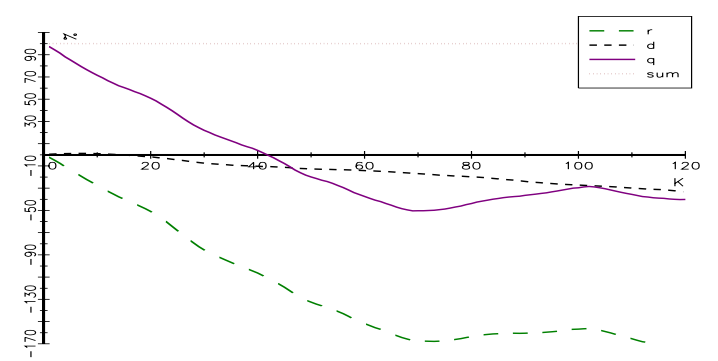

Panel G (NOK)

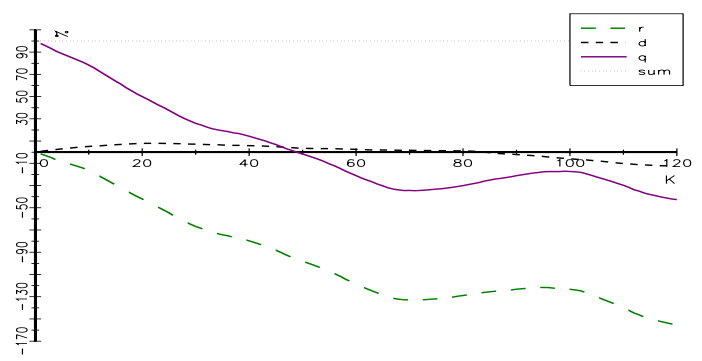

Panel B (CHF)

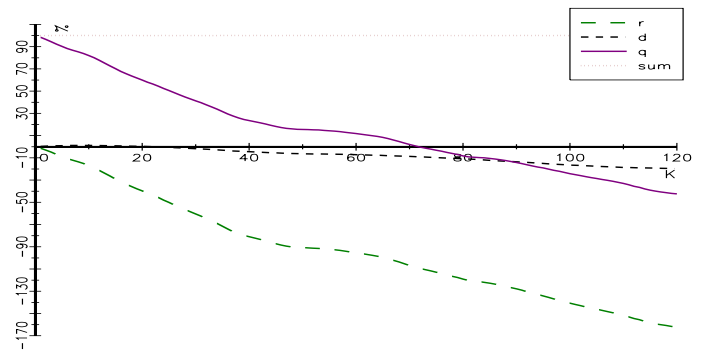

Panel D (JPY)

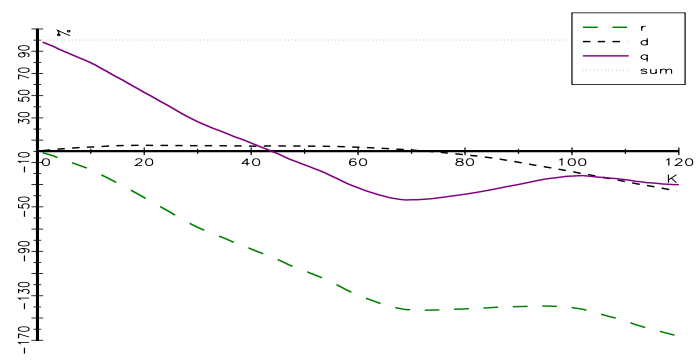

Panel F (DKK)

Figure 3: Term structure of direct long-horizon coefficients (real exchange rate)

This figure plots the term structure of the direct long-horizon predictive coefficients. The predictive slopes are associated with the log real currency return $(r)$, log real interest rate differential $(d)$, and log real spot exchange rate $(q)$. The forecasting variable is the log real exchange rate in all three cases. "Sum" denotes the value of the vajiance decomposition, in \%. The currencies are the Canadian Dollar (CAD), Swiss Franc (CHF), British Pound (GBP), Japanese Yen (JPY), Swedish Krona (SEK), Danish Krone (DKK), and Norwegian Krone (NOK). The long-horizon coefficients are measured in \%, and $K$ represents the number of months ahead. The sample is 1978:07-2011:12. 


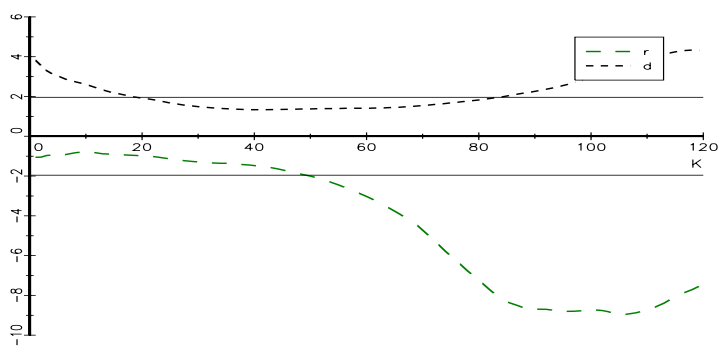

Panel A (CAD)

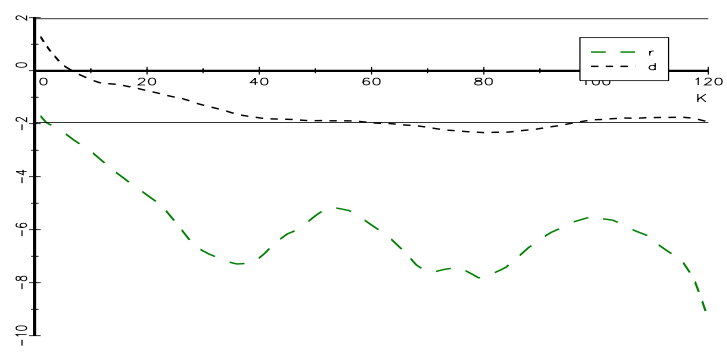

Panel C (GBP)

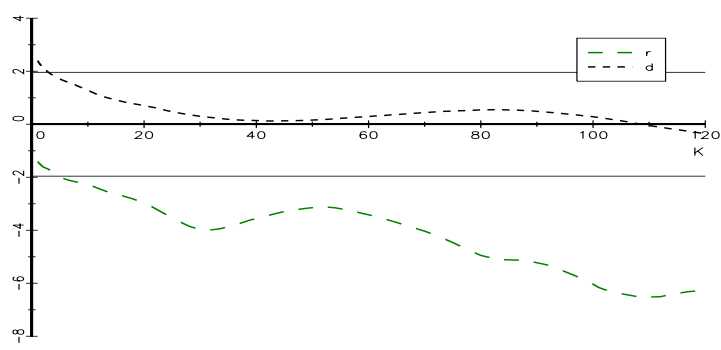

Panel E (SEK)

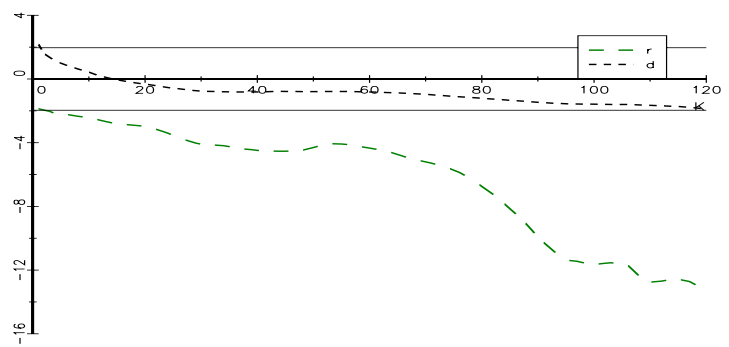

Panel G (NOK)

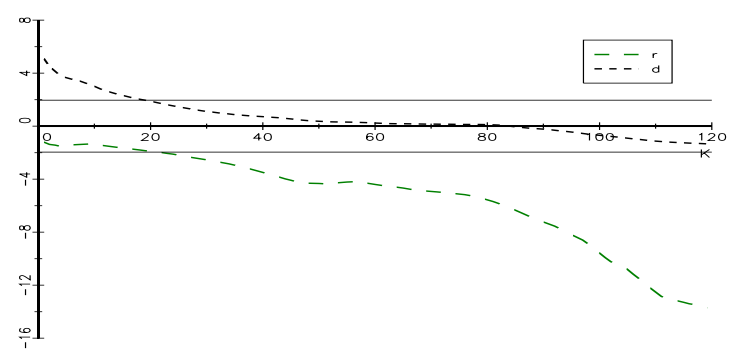

Panel B (CHF)

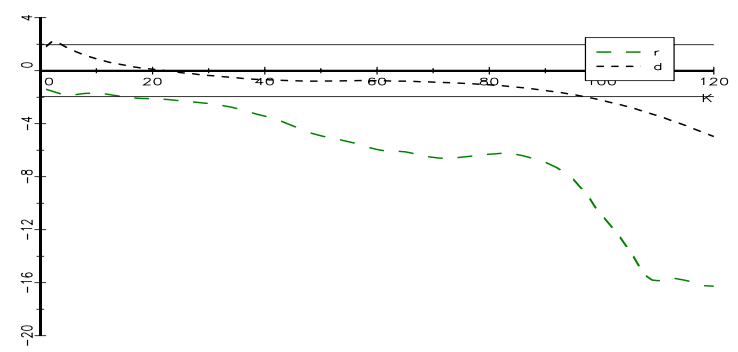

Panel D (JPY)

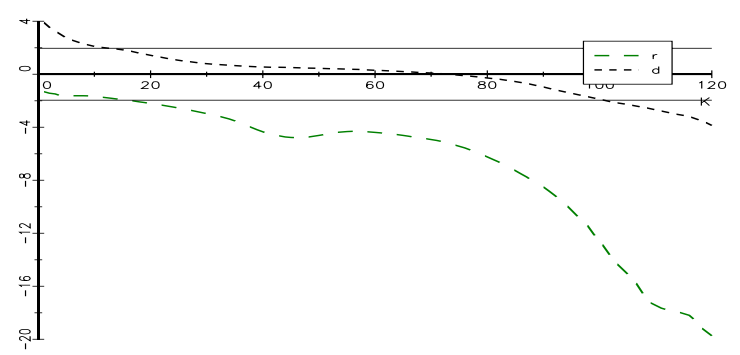

Panel F (DKK)

Figure 4: Term structure of $t$-stats for direct long-horizon coefficients (real exchange rate) This figure plots the term structure of the Newey-West $t$-statistics associated with the direct long-horizon predictive coefficients. The predictive slopes are associated with the log real currency return $(r)$ and log real interest rate differential ( $d$ ). The forecasting variable is the log real exchange rate. The currencjgg are the Canadian Dollar (CAD), Swiss Franc (CHF), British Pound (GBP), Japanese Yen (JPY), Swedish Krona (SEK), Danish Krone (DKK), and Norwegian Krone (NOK). The horizontal lines represent the $5 \%$ critical values $(-1.96,1.96) . \quad K$ represents the number of months ahead. The sample is $1978: 07-2011: 12$. 


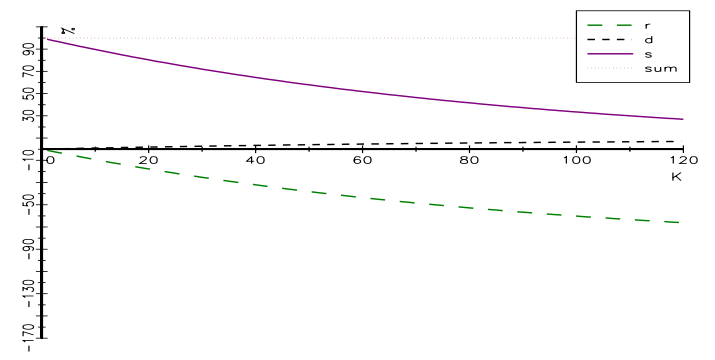

Panel A (CAD)

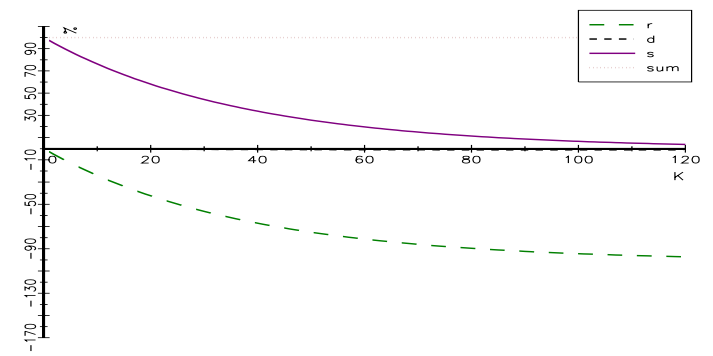

Panel C (GBP)

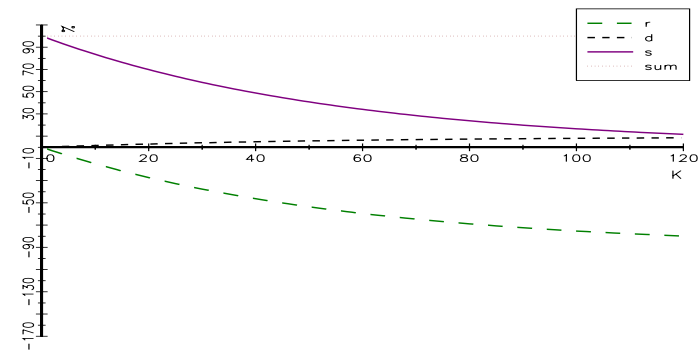

Panel E (SEK)

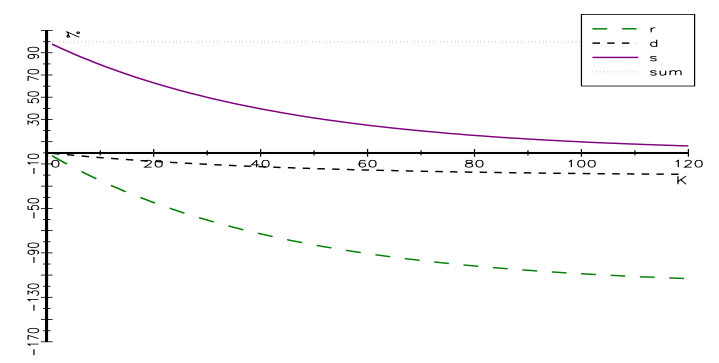

Panel G (NOK)

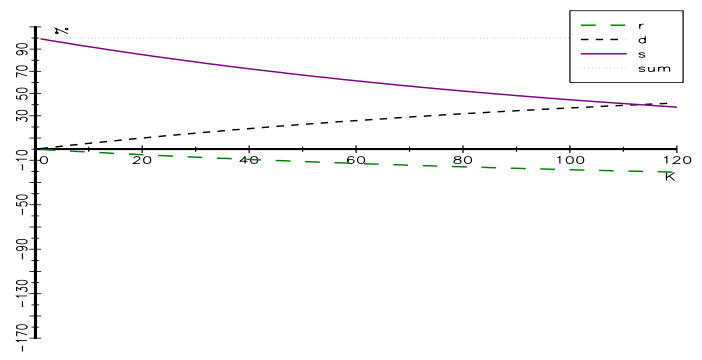

Panel B (CHF)

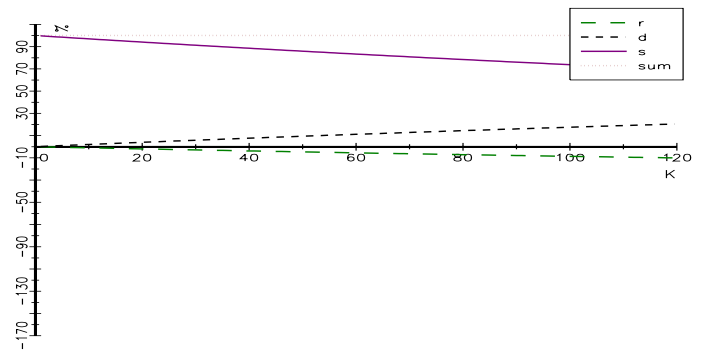

Panel D (JPY)

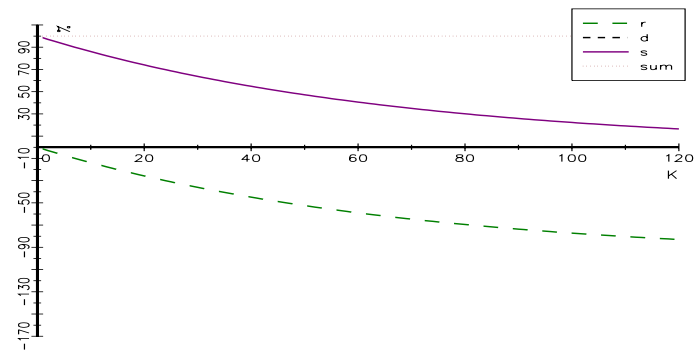

Panel F (DKK)

Figure 5: VAR-based term structure of long-horizon coefficients

This figure plots the term structure of the VAR-based long-horizon predictive coefficients. The predictive slopes are associated with the log return $(r)$, log interest rate differential $(d)$, and log spot exchange rate $(s)$. The forecasting variable is the log exchange rate in all three cases. "Sum" denotes the value of the variance decgmposition, in \%. The currencies are the Canadian Dollar (CAD), Swiss Franc (CHF), British Pound (GBP), Japanese Yen (JPY), Swedish Krona (SEK), Danish Krone (DKK), and Norwegian Krone (NOK). The long-horizon coefficients are measured in \%, and $K$ represents the number of months ahead. The sample is 1978:07-2011:12. 


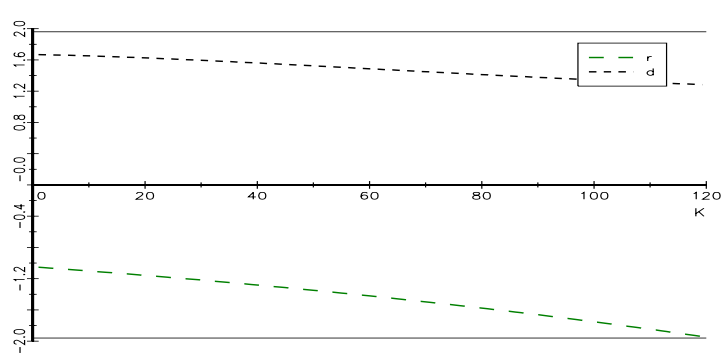

Panel A (CAD)

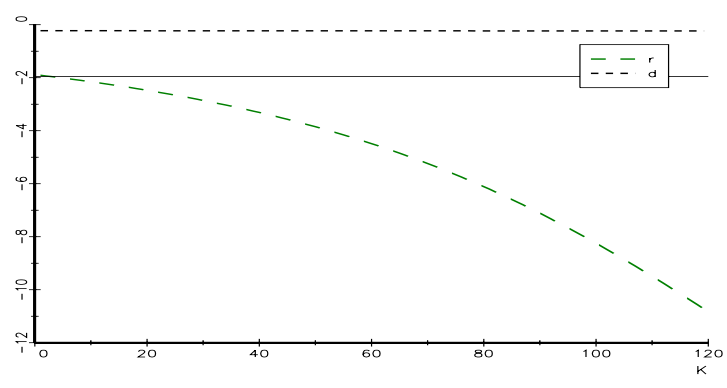

Panel C (GBP)

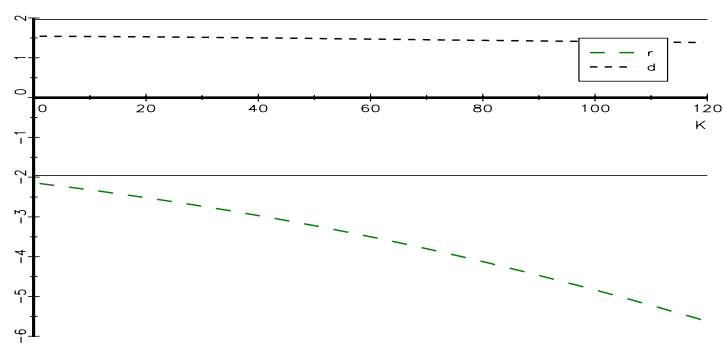

Panel E (SEK)

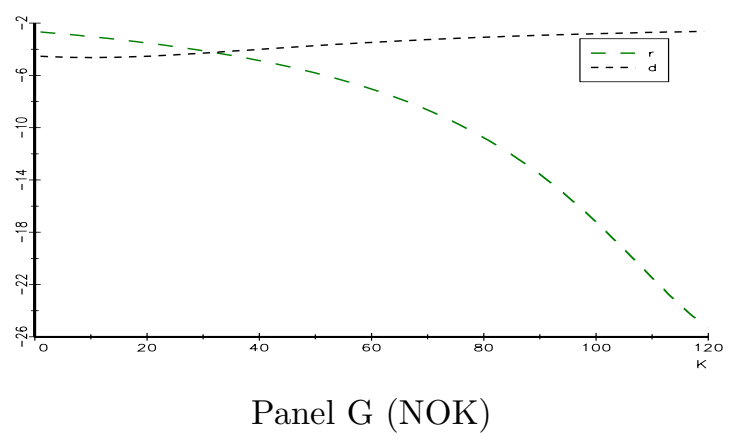

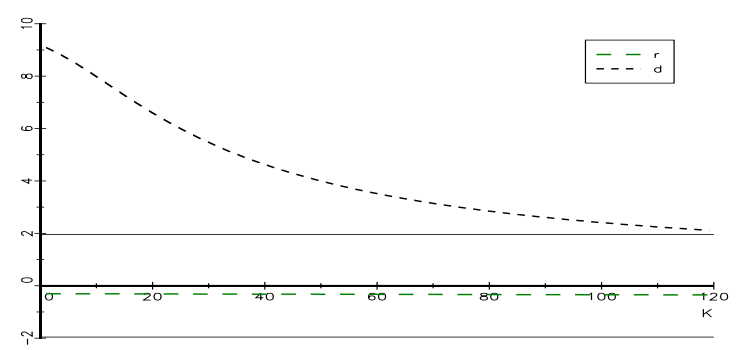

Panel B (CHF)

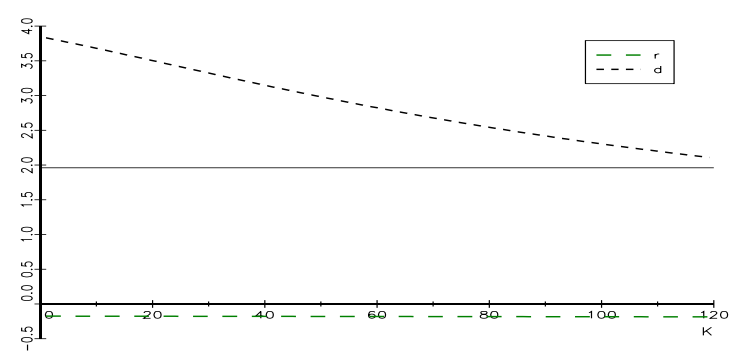

Panel D (JPY)

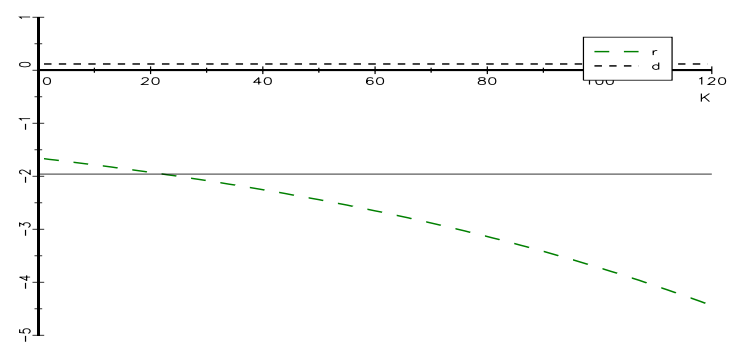

Panel F (DKK)

Figure 6: Term structure of $t$-stats for VAR-based long-horizon coefficients

This figure plots the term structure of the Newey-West $t$-statistics associated with the VAR-based long-horizon predictive coefficients. The predictive slopes are associated with the log return $(r)$ and log interest rate differential (d). The forecasting variable is the log exchange rate. The currencies are tbe Canadian Dollar (CAD), Swiss Franc (CHF), British Pound (GBP), Japanese Yen (JPY), Swedish Krona (SEK), Danish Krone (DKK), and Norwegian Krone (NOK). The horizontal lines represent the $5 \%$ critical values $(-1.96,1.96) . \quad K$ represents the number of months ahead. The sample is $1978: 07-2011: 12$. 


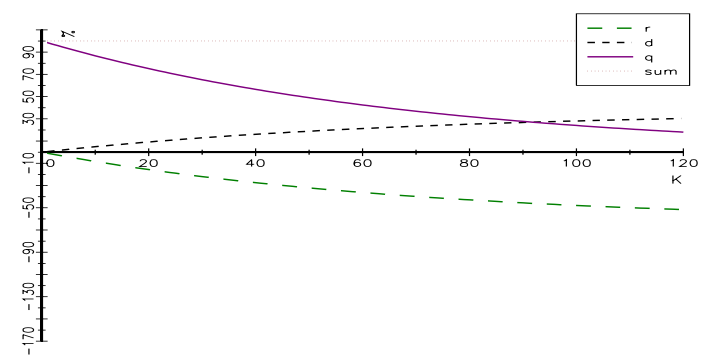

Panel A (CAD)

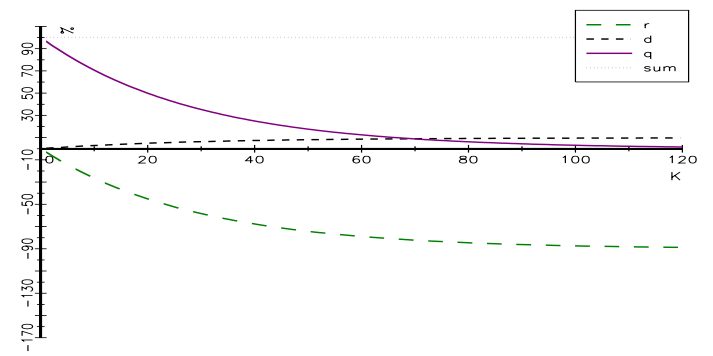

Panel C (GBP)

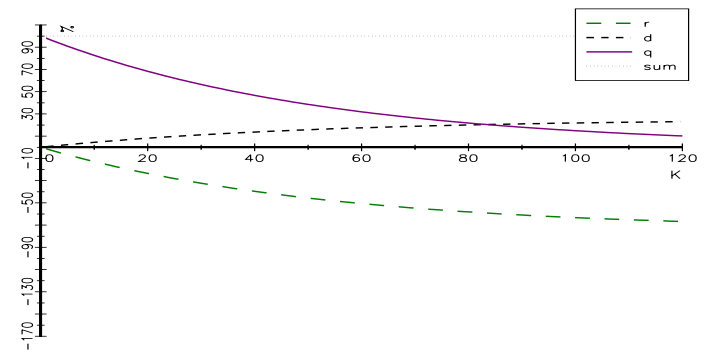

Panel E (SEK)

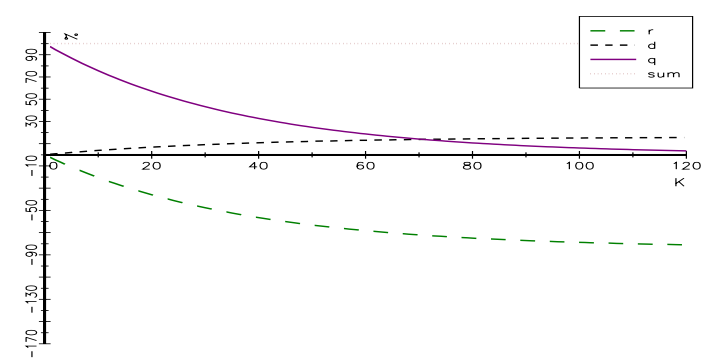

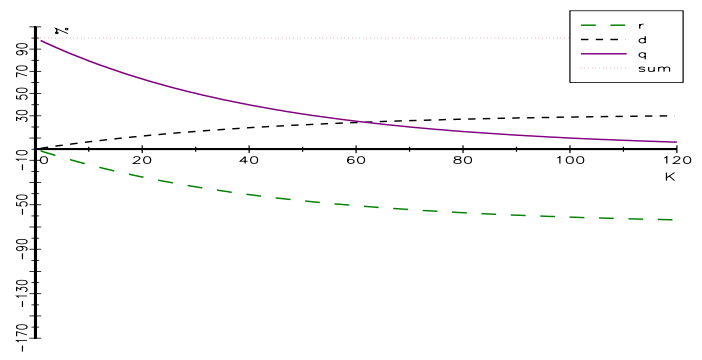

Panel B (CHF)

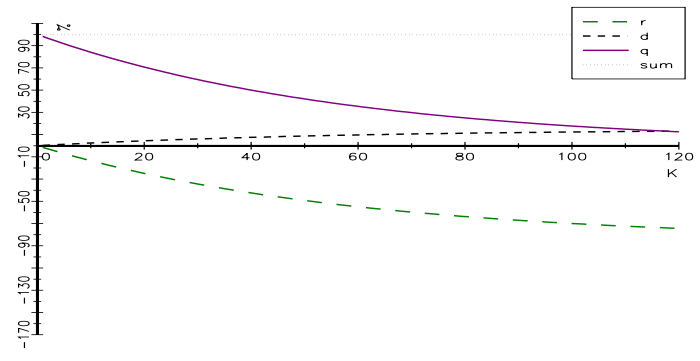

Panel D (JPY)

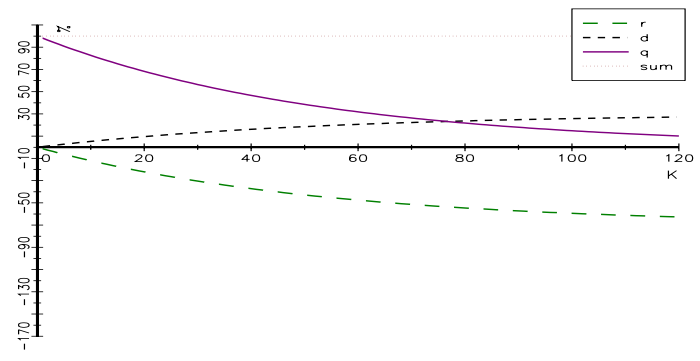

Panel F (DKK)

Panel G (NOK)

Figure 7: VAR-based term structure of long-horizon coefficients (real exchange rate)

This figure plots the term structure of the VAR-based long-horizon predictive coefficients. The predictive slopes are associated with the log real currency return $(r), \log$ real interest rate differential $(d)$, and log real spot exchange rate $(q)$. The forecasting variable is the log real exchange rate in all three cases. "Sum" denotes the value of the 3 gance decomposition, in \%. The currencies are the Canadian Dollar (CAD), Swiss Franc (CHF), British Pound (GBP), Japanese Yen (JPY), Swedish Krona (SEK), Danish Krone (DKK), and Norwegian Krone (NOK). The long-horizon coefficients are measured in \%, and $K$ represents the number of months ahead. The sample is 1978:07-2011:12. 


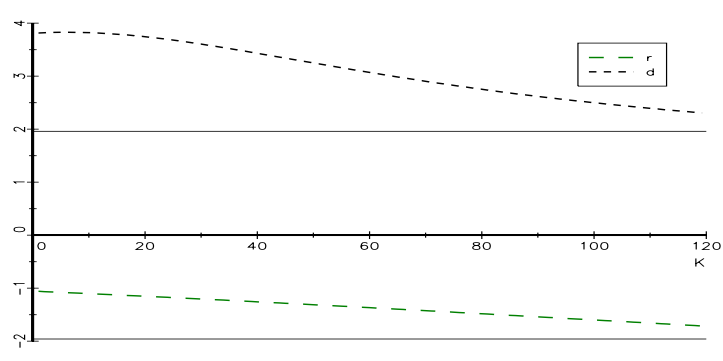

Panel A (CAD)

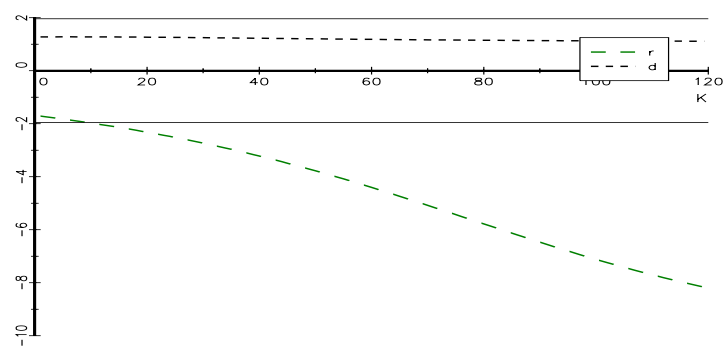

Panel C (GBP)

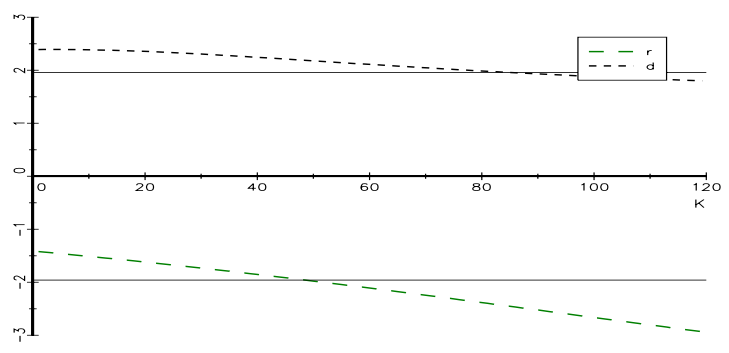

Panel E (SEK)

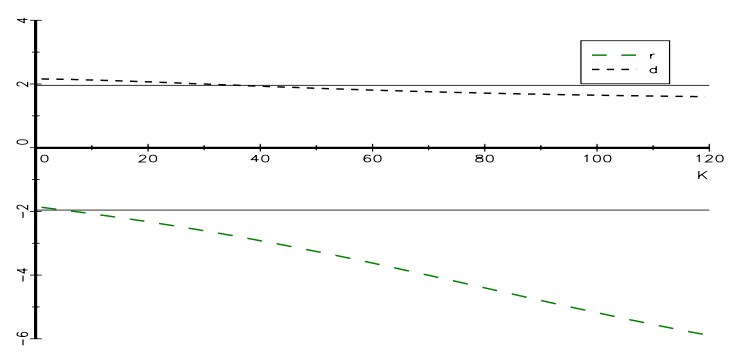

Panel G (NOK)

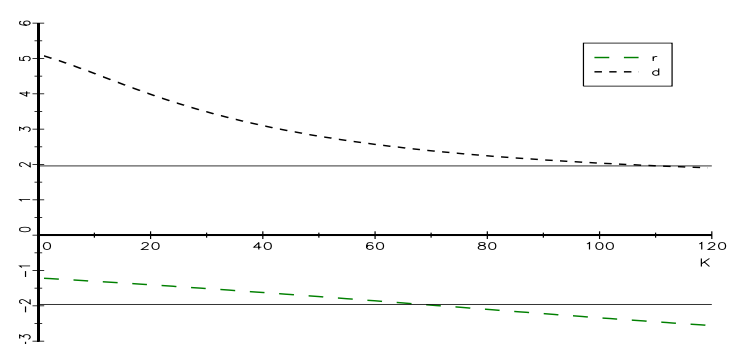

Panel B (CHF)

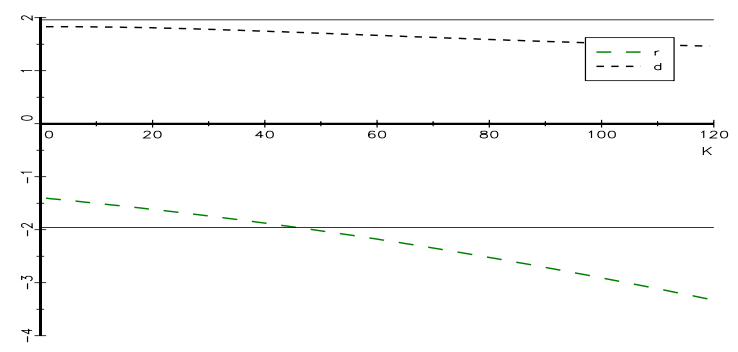

Panel D (JPY)

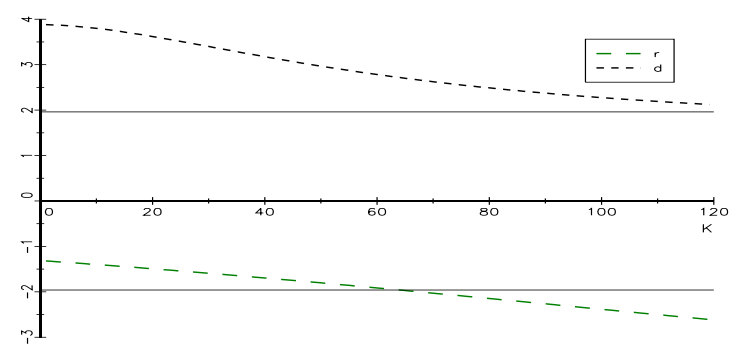

Panel F (DKK)

Figure 8: Term structure of $t$-stats for VAR-based coefficients (real exchange rate)

This figure plots the term structure of the Newey-West $t$-statistics associated with the VAR-based long-horizon predictive coeffcients. The predictive slopes are associated with the log real currency return $(r)$ and log real interest rate differential $(d)$. The forecasting variable is the log real exchange rate. The currengigs are the Canadian Dollar (CAD), Swiss Franc (CHF), British Pound (GBP), Japanese Yen (JPY), Swedish Krona (SEK), Danish Krone (DKK), and Norwegian Krone (NOK). The horizontal lines represent the $5 \%$ critical values $(-1.96,1.96) . \quad K$ represents the number of months ahead. The sample is $1978: 07-2011: 12$. 